\title{
Mechanistic Investigation of LSW/Surfactant/Alkali Synergism for Enhanced Oil Recovery: Fluid-Fluid Interactions
}

\author{
Ali Esfandiarian, Amin Azdarpour,* Rafael M. Santos,* Erfan Mohammadian, Hossein Hamidi, \\ Milad Sedaghat, and Parham B. Dehkordi
}

Cite This: ACS Omega 2020, 5, 30059-30072

Read Online
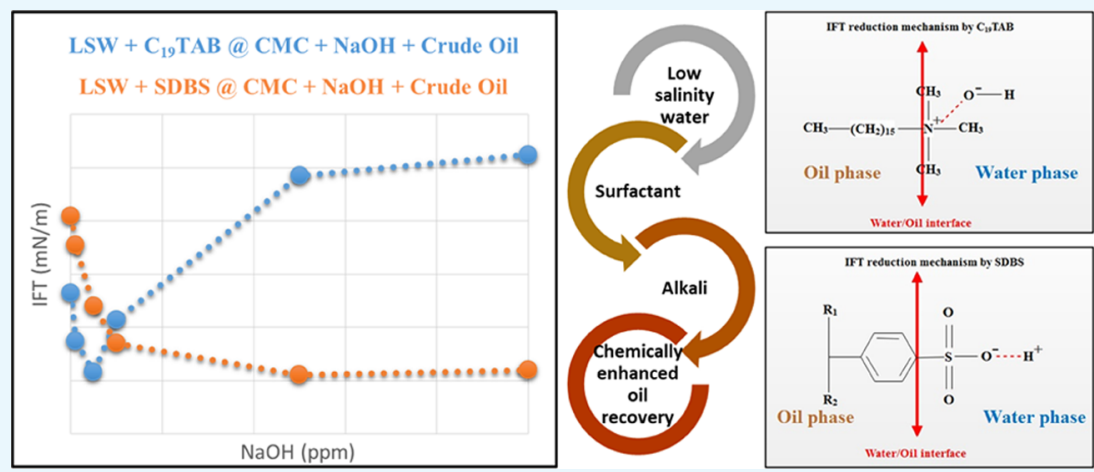

ABSTRACT: The combination of chemical enhanced oil recovery (CEOR) and low salinity water (LSW) flooding is one of the most attractive enhanced oil recovery (EOR) methods. While several studies on CEOR have been performed to date, there still exists a lack of mechanistic understanding on the synergism between surfactant, alkali and LSW. This synergism, in terms of fluidfluid interactions, is experimentally investigated in this study, and mechanistic understanding is gained through fluid analysis techniques. Two surfactants, one cationic and one anionic, namely an alkyltrimethylammonium bromide $\left(\mathrm{C}_{19} \mathrm{TAB}\right)$ and sodium dodecylbenzenesulfonate (SDBS), were tested, together with $\mathrm{NaOH}$ used as the alkali, diluted formation brine used as the LSW, and the crude oil was collected from an Iranian carbonate oil reservoir. Fluids were analyzed using pendant drop method for interfacial tension (IFT) measurement, and Fourier transform infrared spectroscopy for determination of aqueous and oleic phase chemical interaction. The optimum concentration of LSW for IFT reduction was investigated to be 1000 ppm. Additionally, both surfactants reduced IFT significantly, from $28.86 \mathrm{mN} / \mathrm{m}$ to well below $0.80 \mathrm{mN} / \mathrm{m}$, but in the presence of optimal alkali concentration the IFT dropped further to below $0.30 \mathrm{mN} / \mathrm{m}$. IFT reduction by alkali was linked to the production of three different types of in situ anionic surfactants, while in the case of anionic and cationic surfactants, saponification reactions and the formation of the $\mathrm{C}_{19} \mathrm{TAOH}$ alcohol, respectively, were linked to IFT reduction. The critical micelle concentration and optimal alkali concentration when using cationic $\mathrm{C}_{19} \mathrm{TAB}$ were significantly lower than with the anionic surfactant; respectively: 335 vs 5000 ppm, and 500 vs 5000 ppm. However, it was found that SDBS was more compatible with $\mathrm{NaOH}$ than $\mathrm{C}_{19} \mathrm{TAB}$, due to occurrence of alkali deposition with the latter beyond the optimal point.

\section{INTRODUCTION}

Increasing demand for crude oil and their limited resources have forced petroleum production companies to use enhanced oil recovery (EOR) methods. Chemically enhanced oil recovery (CEOR) is one of the most effective EOR methods in beneficially altering reservoir rock and fluid properties, enabling increased crude oil production. One of the most commonly adopted CEOR processes is surfactant flooding, which has been shown to improve oil recovery significantly. ${ }^{1-8}$ Oil recovery extent is a function of rock and fluid properties, such as pore structure, capillary pressure, interfacial tension (IFT), rock wettability, mobility ratio, and reservoir heterogeneity. Thus, during surfactant flooding, IFT reduction, micro-emulsion formation, and wettability alteration are mechanisms that result in greater oil recovery extent compared to conventional water flooding. ${ }^{8-15}$

Over the last two decades, $\mathrm{C}_{n} \mathrm{TAB}$ - and sulfonate-based surfactants have received significant attention in EOR studies. Austad and Milter ${ }^{16}$ and Standnes and Austad ${ }^{17-19}$ worked on the effects of several such cationic surfactants, including $\mathrm{C}_{8} \mathrm{TAB}$,

Received: September 11, 2020

Accepted: November 3, 2020

Published: November 13, 2020 
$\mathrm{C}_{10} \mathrm{TAB}, \mathrm{C}_{12} \mathrm{TAB}$, and $\mathrm{C}_{16} \mathrm{TAB}$, and reported that wettability alteration of surfactant flooding from oil-wetting to waterwetting conditions can improve oil recovery significantly, from $5 \%$ when using pure brine to approximately $70 \%$ after surfactant flooding. Kumar et al., ${ }^{20}$ investigated the interfacial interaction of four different types of cationic surfactants, including $\mathrm{C}_{10} \mathrm{TAB}$, $\mathrm{C}_{15} \mathrm{TAB}, \mathrm{C}_{16} \mathrm{TAB}$, and $\mathrm{C}_{19} \mathrm{TAB}$, as well as their effects on wettability alteration of oil-wetting reservoirs. They reported critical micelle concentration (CMC) of $\mathrm{C}_{10} \mathrm{TAB}, \mathrm{C}_{15} \mathrm{TAB}$, $\mathrm{C}_{16} \mathrm{TAB}$, and $\mathrm{C}_{19} \mathrm{TAB}$ to be $120,14,0.9$, and $1 \mathrm{mM}$, respectively. Also, the IFT between crude oil and $\mathrm{C}_{10} \mathrm{TAB}, \mathrm{C}_{15} \mathrm{TAB}, \mathrm{C}_{16} \mathrm{TAB}$, and $\mathrm{C}_{19} \mathrm{TAB}$, at their respective $\mathrm{CMC}$ concentrations, were found to be $7,0.23,7.6$, and $0.5 \mathrm{mN} / \mathrm{m}$, respectively. ${ }^{20}$

Injection of surfactants at high concentrations enhances the overall displacement efficiency, by forming micelles; however, economical constrains exist at high concentrations. Standnes and Austad ${ }^{21,22}$ and Strand et al. ${ }^{23}$ utilized both novel and commercial cationic surfactants, including $\mathrm{C}_{10} \mathrm{NH}_{2}$, arquad, and dodigen, to recover $50-90 \%$ of the original oil; however, the required concentration of the novel surfactant was relatively high (nearly $1 \mathrm{wt} \%$ ), which made it unattractive to be used. ${ }^{21-23}$ In order to overcome this limitation, alkali co-surfactants can be added to dilute surfactant solutions, thus making the CEOR process more efficient from economical point of view. ${ }^{24-27}$ Alkali co-surfactants are more compatible with crudes with high acid numbers, since a surfactant is formed in situ by the reaction of the alkali and certain acidic components of crude oil. ${ }^{28-30}$ Dehghan et al., ${ }^{31}$ using two sulfonate-based surfactants and two commercial sulfate-based surfactants in conjunction with sodium metaborate as the alkaline co-surfactant, concluded that in situ soap generation during alkaline-surfactant (AS) flooding facilitates micro-emulsion generation in the solution. In addition, surfactant adsorption onto rock surfaces is reduced significantly in the presence of alkali. ${ }^{26,27,29,32}$

The role of AS flooding on oil recovery has been linked by Chen et al. ${ }^{33}$ and Liu et al. ${ }^{34}$ to IFT reduction, wherein greater IFT reduction has been reported for AS flooding compared to alkali- or surfactant-enhanced flooding alone. Zhang et al. ${ }^{35}$ pointed that oil recovery enhancement by AS flooding increased with increasing $\mathrm{NaOH}$ concentration up to a threshold value of $0.5 \mathrm{wt} \%$ (this value was much lower for AS flooding compared to alkali-only flooding), beyond which further increasing the concentration had minimal effect on oil recovery.

Nowadays, with the decline in world oil prices, the trend towards more cost-effective methods of CEOR, such as smart water flooding or low salinity water flooding (LSWF), has increased. Although these methods are more cost-effective than other CEOR methods, they recover only $4 \%$ additional oil over the recovery from high-salinity injection. ${ }^{36}$ Combination of LSW with 1000 ppm (1 wt \%) alkali/surfactant reportedly can increase the oil recovery by $7-17 \%$ of original oil in place (OOIP). ${ }^{36}$ In addition, minor formation damage and more IFT reduction have been observed based on the literature in various experiments. ${ }^{24,36-39}$ Comparison of the recovery from LSWsurfactant and LSW-alkali indicates that higher oil recovery can be attained with surfactant than with alkali. ${ }^{36}$ Higher efficiency with surfactant can be attributed to the lower achievable IFT with surfactant than with alkali. Pal et al. stated that salt addition to the surfactant solution plays a synergistic role in further decreasing IFT to ultra-low magnitudes. ${ }^{40}$ As previously noted, alkali is used as a co-surfactant in AS processes to improve the impact of surfactant for EOR purposes. Therefore, surfactants can be used as the main chemical agent and alkali plays the role of an additive in LSW-AS system. The results that obtained from literature emphasize the benefits of hybrid methods for the improvement of oil recovery.

Although several studies have been conducted so far on AS flooding, some contradictory results still exist. Some researchers claim positive interaction of alkali and surfactant and some others claim otherwise. ${ }^{29-31,41,42}$ In addition, different interactions may occur between injected chemicals, low salinity water (LSW), another approach used for oil recovery enhancement, ${ }^{43}$ and crude oils, due the nature of each crude oil. These are research questions that need to be explored experimentally. Thus, the current study was designed and performed to provide a better understanding of the synergisms and mechanisms involved during surfactant/alkali/LSW flooding, in view of enhanced oil recovery, with a focus on fluid-fluid interactions. To this end, crude oil was collected from one of the Iranian carbonate oil reservoirs. Fluid-fluid (i.e., oil-water) interactions were investigated in detail using two different surfactants an alkyltrimethylammonium bromide $\left(\mathrm{C}_{19} \mathrm{TAB}\right)$ and sodium dodecylbenzenesulfonate (SDBS), with $\mathrm{NaOH}$ as the alkali, and LSW as the aqueous medium. The fluid-fluid interactions were characterized by Fourier-transform infrared (FT-IR) spectroscopy, electrical conductivity (EC) and $\mathrm{pH}$ analysis, and pendant drop IFT measurement.

\section{MATERIALS AND METHODS}

2.1. Chemicals. Two types of surfactants were used: an anionic surfactant (SDBS) with the chemical formula of $\mathrm{C}_{12} \mathrm{H}_{25} \mathrm{C}_{6} \mathrm{H}_{4} \mathrm{SO}_{3} \mathrm{Na}$ (Sigma-Aldrich), and one cationic surfactant $\left(\mathrm{C}_{19} \mathrm{TAB}\right)$ with the chemical formula of $\mathrm{C}_{19} \mathrm{H}_{42} \mathrm{BrN}$ (Merck). Reagent grade $\mathrm{NaOH}$ (Sigma-Aldrich) was used as the alkali.

2.2. Fluids. Crude oil with API of 31.56 and $2.8(\mathrm{mg} \mathrm{KOH} / \mathrm{g}$ oil) acid number, and formation brine (FB) with total dissolved solids (TDS) of 97,645 ppm (mg/L), were both collected from one of the Iranian carbonate oil reservoirs. Table 1 presents the

Table 1. SARA Analysis of the Crude Oil Used in This Study

$\begin{array}{cccc}\text { saturates }(\mathrm{wt} \%) & \text { aromatic }(\mathrm{wt} \%) & \text { resin }(\mathrm{wt} \%) & \text { asphaltene (wt \%) } \\ 53.35 & 32.28 & 9.78 & 4.59\end{array}$

saturate, aromatic, resin, and asphaltene (SARA) analysis of this crude oil and Table 2 presents its compositional analysis. Tables 3 and 4 presents the compositional analysis of the collected FB and the prepared LSW, and Table 4 present physical properties of the FB. To prepare LSW, the FB was diluted by deionized water (DIW) to a salinity of 1000 (dFB1000), 2000 (dFB2000), 3000 (dFB3000) and 5000 (dFB5000) ppm. These concentrations of LSW were selected due to the recommendation of Mcguire et al., ${ }^{44}$ that is, less than 5000 ppm. Moreover, using diluted FB is the best operational method for preparing LSW, as $\mathrm{dFB}$ will not have the potential problems of incompatibility between the injected low-salinity water and FB.

2.3. Experimental Procedure. Four different laboratory tests were conducted to assess liquid-liquid interactions: compatibility and stability bottle test, pendant drop IFT measurement, electrical conductivity (EC) and Fourier-transform infrared (FT-IR) spectroscopy analysis. Bottle test was used for evaluating the compatibility and stability of chemical slug with saline water under high temperature condition as a function of time. IFT and EC measurements were used for CMC determination, while Fourier-transform infrared spectroscopy 
Table 2. Compositional Analysis of Crude Oil Used in This Study

$\begin{array}{ccccccccccccccc}\text { Component } & \mathrm{C}_{1} & \mathrm{C}_{2} & \mathrm{C}_{3} & \mathrm{i}-\mathrm{C}_{4} & \mathrm{n}-\mathrm{C}_{4} & \mathrm{i}-\mathrm{C}_{5} & \mathrm{n}-\mathrm{C}_{5} & \mathrm{C}_{6} & \mathrm{C}_{7+} & \mathrm{H}_{2} \mathrm{~S} & \mathrm{CO}_{2} \\ \text { Mole \% } & 47.66 & 11.32 & 6.48 & 1.08 & 2.89 & 1.21 & 1.49 & 2.38 & 25.49 & 0 & 0\end{array}$

Table 3. Composition of Formation Brine and Low Salinity Waters Used in This Study

\begin{tabular}{llllll}
\multicolumn{1}{c}{ Ion } & FB (ppm) & dFB1000 & dFB2000 & dFB3000 & dFB5000 \\
$\mathrm{Ca}^{2+}$ & 3,800 & 39 & 78 & 117 & 195 \\
$\mathrm{Mg}^{2+}$ & 1,944 & 20 & 40 & 60 & 100 \\
$\mathrm{Na}^{+}$ & 38,406 & 393 & 786 & 1,179 & 1,965 \\
$\mathrm{HCO}_{3}^{-}$ & 45 & 1 & 2 & 3 & 5 \\
$\mathrm{SO}_{4}^{2-}$ & 1,200 & 12 & 24 & 36 & 60 \\
$\mathrm{Cl}^{-}$ & 52,250 & 535 & 1,070 & 1,605 & 2,675 \\
$\mathrm{TDS}$ & 97,645 & 1000 & 2000 & 3000 & 5000 \\
\hline
\end{tabular}

Table 4. Physical Properties of Formation Brine Used in This Study

\begin{tabular}{ll}
\multicolumn{1}{c}{ Properties } & \multicolumn{1}{c}{ Value } \\
Electrical conductivity $(\mu \mathrm{s} / \mathrm{cm})$ & 184,100 \\
Total hardness $(\mathrm{mg} / \mathrm{L})$ & 17,500 \\
Density at $20 \mathrm{C}\left(\mathrm{g} / \mathrm{cm}^{3}\right)$ & 1.1005 \\
Turbidity $(\mathrm{NTU})$ & 0.40 \\
Total alkalinity & 325 \\
Sodium absorption ratio $(\mathrm{SAR})$ & 240.22 \\
Soluble sodium $(\%)$ & 89.93 \\
pH & 7.01
\end{tabular}

(FT-IR) analysis was used to determine the chemical mechanisms involved.

The compatibility of the surfactant/alkaline-surfactant solutions in four brines (dFB1000, dFB2000, and dFB3000, and dFB5000) were examined by conducting bottle tests at reservoir temperature $\left(80{ }^{\circ} \mathrm{C}\right)$. No deposits or lumps were observed after 1 month.

Pendant drop method, commonly known as axisymmetric drop shape analysis (ADSA), is commonly used for determining the IFT at reservoir conditions. ${ }^{45,46}$ The IFT400 apparatus, illustrated in Figure 1, was used for determining the IFT

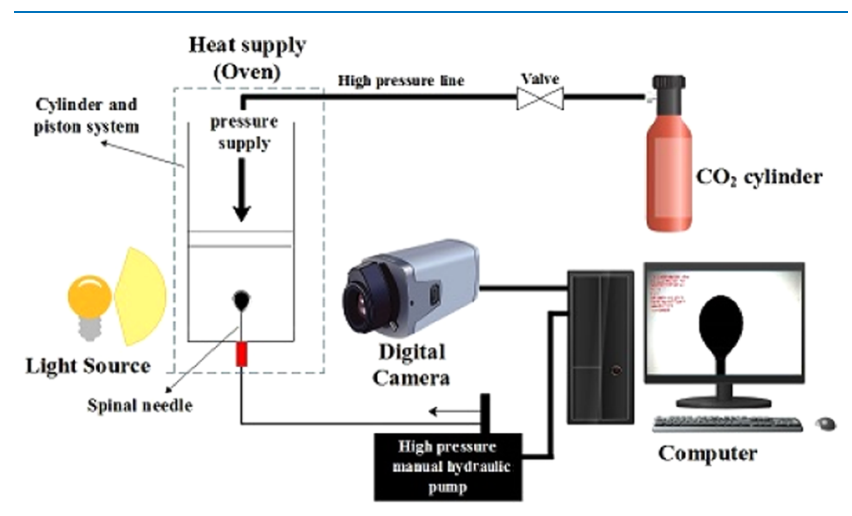

Figure 1. Schematic diagram of IFT400 for IFT measurement.

between different solutions and the crude oil. The maximum operating temperature and pressure of the apparatus were 204 ${ }^{\circ} \mathrm{C}\left(400{ }^{\circ} \mathrm{F}\right)$ and $414 \mathrm{bar}(6000 \mathrm{psi})$, respectively. The IFT400 setup consists of a $50 \mathrm{~cm}^{3}$ stainless steel chamber, a vacuum pump, gas tank, fluid tank, heating oven, a digital camera, a positive displacement pump, and a quartz window. The captured images were analyzed using an image processing code compiled in LabVIEW, which was provided by the manufacturer of the IFT400 apparatus (Fars Enhanced Oil Recovery Technology Company, Iran).

Solutions containing surfactants alone, or surfactants together with $\mathrm{NaOH}$, were prepared using LSW. Initially, the IFT of surfactant-LSW solutions $\left(\mathrm{C}_{19} \mathrm{TAB}\right.$ or $\mathrm{SDBS}$, with concentrations of 0 to $10000 \mathrm{ppm}$ ) in contact with crude oil, at $80^{\circ} \mathrm{C}$ (reservoir temperature), was determined, and the CMC of each surfactant solution in the presence of crude oil was estimated from the plot of IFT versus surfactant concentration. ${ }^{29,47}$ The $\mathrm{CMC}$ is referred to as the concentration of the solution in which the first micelle is formed; that is, micelles accumulate only when the surfactant concentration is higher than the CMC value. Next, LSW solutions with constant surfactant concentration (the CMC value previously determined, namely $335 \mathrm{ppm}$ for $\mathrm{C}_{19} \mathrm{TAB}$ and $5000 \mathrm{ppm}$ for SDBS), and varying concentrations of $\mathrm{NaOH}$ (100-10000 ppm), were prepared; the IFT of these solutions in contact with crude oil, at $80{ }^{\circ} \mathrm{C}$ (reservoir temperature), was measured for finding the optimum concentration of alkali. Each IFT test was repeated three times, and the uncertainty $0.001 \mathrm{mN} / \mathrm{m}$. Moreover, the reported value of IFT is equilibrium IFT, and the IFT value closest to the average of three IFT values is selected as the reported value of IFT.

The EC values of different solutions were measured using a digital multimeter (model PCT-407), with uncertainty of 0.01 $\mu \mathrm{s} . \mathrm{cm}^{-1}$. The solutions used for EC measurements were the same as the aqueous solutions used in IFT tests.

Finally, for FT-IR testing, a mixture of aqueous and oleic phase was extracted from the aqueous/oleic interface using a spinal needle. These two-phase mixtures were prepared using volumetric ratio of 50:50 of crude oil and aqueous phase in a bottle that was shaken for 10 minutes, then it was rested at $80^{\circ} \mathrm{C}$ (reservoir temperature) for $24 \mathrm{~h}$. FT-IR analysis of the extracted mixture was recorded between 400 and $4000 \mathrm{~cm}^{-1}$ using $\mathrm{KBr}$ pellet techniques on a Perkin Elmer RX1 infrared (IR) spectrophotometer. The spectra were interpreted using IRPal V2.0 FT-IR spectra analysis software (Dr. Wolf van Heeswijk). Samples of raw and contacted crude oil analyzed in this form were: crude oil; crude oil $+\mathrm{NaOH}(1000 \mathrm{ppm})$; crude oil + $\mathrm{C}_{19} \mathrm{TAB}(335 \mathrm{ppm})$; crude oil $+\mathrm{C}_{19} \mathrm{TAB}(335 \mathrm{ppm})+\mathrm{NaOH}$ $(500 \mathrm{ppm})$; crude oil + SDBS (5000 ppm); and crude oil + SDBS $(5000 \mathrm{ppm})+\mathrm{NaOH}(5000 \mathrm{ppm})$. These solutions were selected according the optimum chemical concentrations resulting from IFT tests.

\section{RESULTS AND DISCUSSION}

3.1. IFT Measurements. The IFT measurements in this study were divided into three parts. In the first part, the IFT between waters (DIW, dFB1000, dFB2000, dFB3000, and dFB5000) and crude oil were determined, to determine a baseline for comparison of enhancement effects and find the optimum concentration of LSW (diluted FB). In the second part, the IFT between different LSW-surfactant solutions and crude oil was determined, and the CMC value of each surfactant was estimated accordingly. These experiments were meant to inform the surfactant concentrations to use in the next part. In the third part, the IFT between LSW-surfactant-alkali solutions 
(with constant surfactant concentration and variable alkali concentration) and crude oil was determined.

In the first part, Figure 2 shows the trend of IFT reduction for different concentrations of diluted FB as LSW. The IFT tests

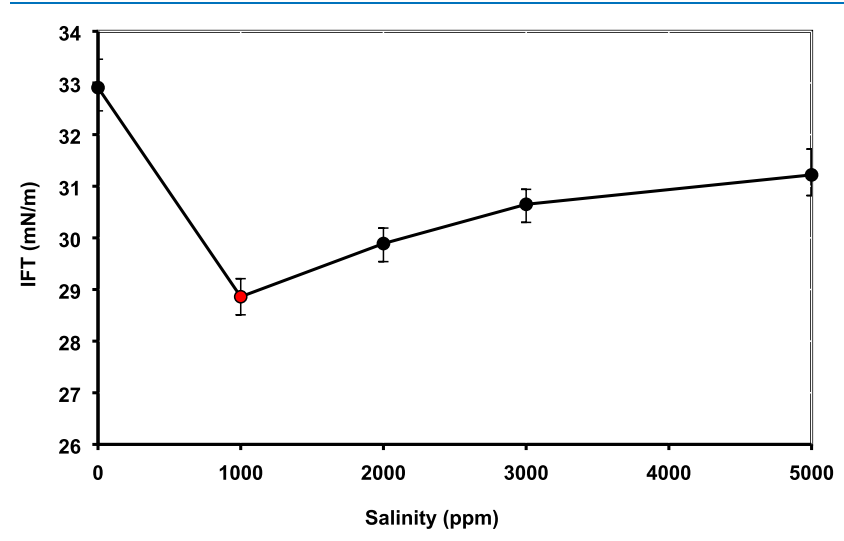

Figure 2. IFT changes of diluted FB at different salinities.

showed that in case of DIW the IFT was $32.91 \mathrm{mN} / \mathrm{m}$, and it decreased to $28.86 \mathrm{mN} / \mathrm{m}$ when $1000 \mathrm{ppm} \mathrm{LSW} \mathrm{(dFB1000)}$ was used instead, while IFT increased after increasing the concentration from 1000 to $5000 \mathrm{ppm}$. In this case the IFT values of 28.86 to 31.22 were achieved, respectively. Therefore, the optimum concentration of dFB is $1000 \mathrm{ppm}$ for this type of crude oil and FB system as pointed with red color in Figure 2. Dabiri and Honarvar ${ }^{48}$ investigated the optimal concentration of surfactant for IFT reduction during LSW flooding. They used the same crude oil as in the present study and concluded that the optimum salinity for diluted FB is 1000 ppm, which serves to confirm that the methodology used here yields similar results to previous studies. This value is also in agreement with the optimal range $(1000-2000 \mathrm{ppm})$ as suggested by Austad et al. ${ }^{49}$

LSW consist of different monovalent and divalent ions that plays a significant role in $\mathrm{pH}$ value. On the other side, $\mathrm{pH}$ of saline waters has a great impact in the saponification mechanism. Some strong alkali cations present in LSW, such as $\mathrm{Na}^{+}$and $\mathrm{K}^{+}$, react with carboxylic acids $\left(\mathrm{COOH}^{-}\right)$of crude oil, and generate soap molecules (sodium soap or potassium soap). ${ }^{50-52}$ Soap molecule is a kind of anionic surfactant that can reduce the IFT. Although LSW has alkali ions, it has some strong acidic ion such as: $\mathrm{SO}_{4}{ }^{2-}$. Furthermore, the presence of $\mathrm{Ca}^{2+}$ and $\mathrm{Mg}^{2+}$ divalent cations in the solution prevents soap making, by reducing the participation of alkali monovalent cations in the reaction. Overall, the ratio of these ions concentration governs the $\mathrm{pH}$ value and the saponification mechanism. The $\mathrm{pH}$ values for dFB1000, dFB2000, dFB3000 and dFB5000 were 8.36, 8.05, 7.71 and 7.43 , respectively. This explains why the effect of alkali cations and saponification mechanism in dFB1000 was greater than with the other diluted FB's. According to Figure 2, the IFT value for dFB 1000 is the lowest among the LSWs. It can be concluded that saponification mechanism has a direct impact on the IFT reduction between LSW and crude oil.

For better interpreting the saponification mechanism, some IFT tests were performed at different concentrations of $\mathrm{NaOH}$, from 100 to $10000 \mathrm{ppm}$ in dFB1000, as shown in Table S1 (SS22-SS26). The IFT value reduces from 28.86 to $0.64 \mathrm{mN} / \mathrm{m}$ by adding $1000 \mathrm{ppm} \mathrm{NaOH}$ to dFB1000, while the $\mathrm{pH}$ value increased from 8.36 to 12.46 . Hence, the $\mathrm{pH}$ is enhanced and saponification mechanism is more intensified by the presence of free $\mathrm{OH}^{-}$. Also, the IFT increases slightly with further increase in alkali concentration (more than $1000 \mathrm{ppm}$ ). This occurs because the $\mathrm{pH}$ value does not change significantly, with primarily an increase in ionic strength of the solution. ${ }^{53}$ Hence, further in situ formation of soap is reduced, and growth of ionic strength leads to increase of the soap solubility in oleic phase, which results in the desorption of surfactant from the oil-water interface into the oleic phase. ${ }^{54}$

In the second part, the effect of surfactant concentration on IFT for solutions prepared in LSW was determined by increasing the concentration of $\mathrm{C}_{19} \mathrm{TAB}$ and SDBS from 0 to $10000 \mathrm{ppm}$. Figure 3 clearly presents the trend of changes in the IFT of these solutions with crude oil. As was expected, increasing the concentration of surfactants resulted in a significant decrease in the IFT. However, after reaching the CMC value of each surfactant, the IFT value nearly stabilized. In case of $\mathrm{C}_{19} \mathrm{TAB}$, the IFT decreased from $28.86 \mathrm{mN} / \mathrm{m}$ to $0.53 \mathrm{mN} / \mathrm{m}$ by increasing the concentration from 0 to $335 \mathrm{ppm}$. Further increasing the $\mathrm{C}_{19} \mathrm{TAB}$ concentration to $10000 \mathrm{ppm}$ had minor effect on IFT, resulting in a value of $0.41 \mathrm{mN} / \mathrm{m}$. On the other

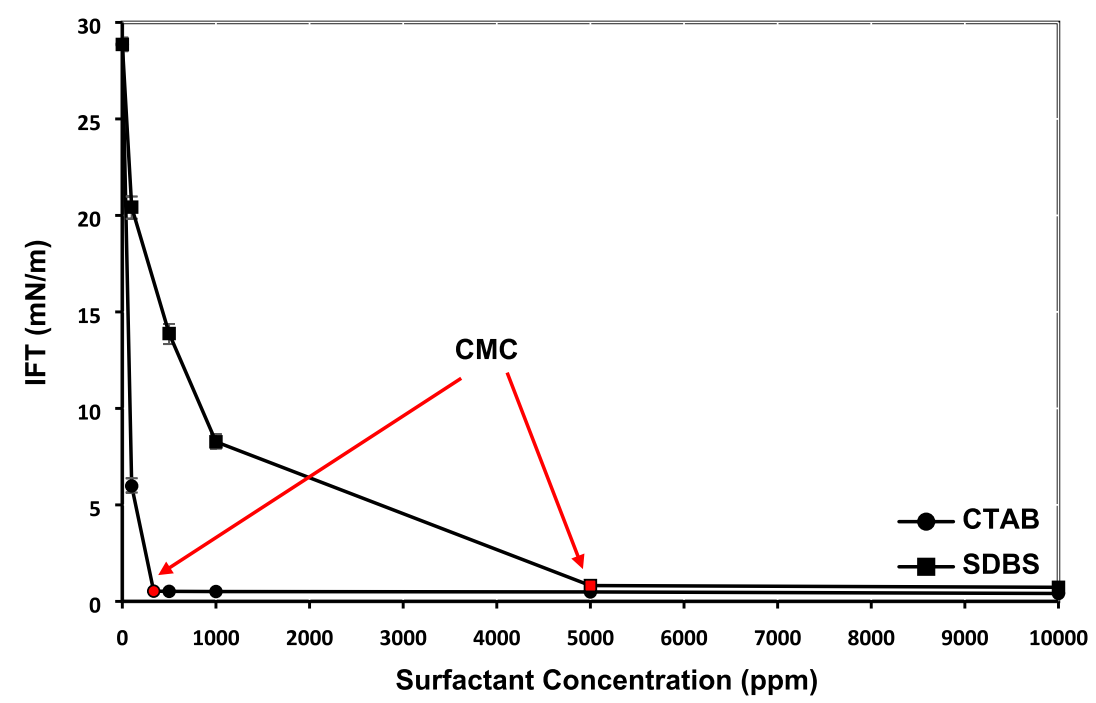

Figure 3. IFT changes of $\mathrm{C}_{19} \mathrm{TAB}(\mathrm{CTAB})$ and $\mathrm{SDBS}$ solutions ( $\mathrm{LSW}+$ different $\mathrm{C}_{19} \mathrm{TAB}$ concentrations and LSW + different SDBS concentrations) with crude oil, and their $\mathrm{CMC}$ values. 

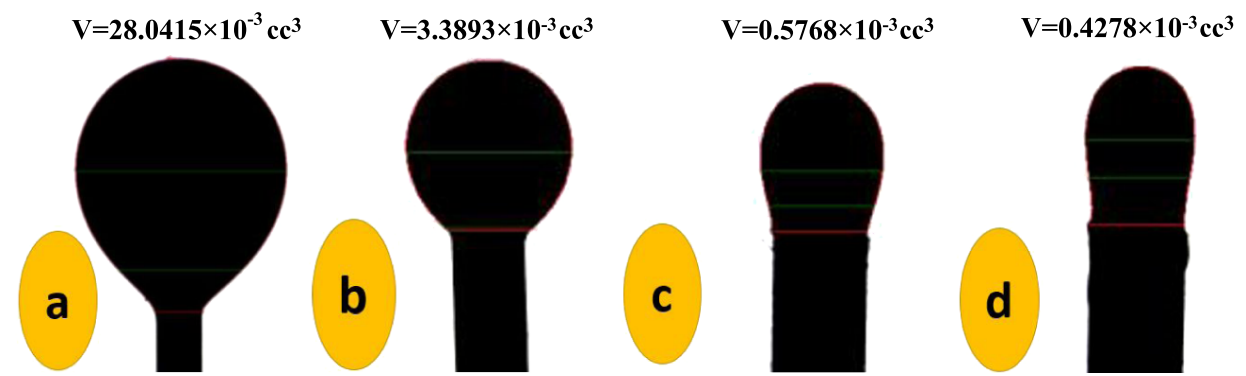

Figure 4. Digital images of pendant drop; (a): LSW and oil drop without $\mathrm{C}_{19} \mathrm{TAB}$; (b): solution of $100 \mathrm{ppm} \mathrm{C}_{19} \mathrm{TAB}$ and oil drop; (c): solution of 335 ppm $\mathrm{C}_{19} \mathrm{TAB}$ and oil drop; (d) solution of $5000 \mathrm{ppm} \mathrm{C}_{19} \mathrm{TAB}$ and oil drop.
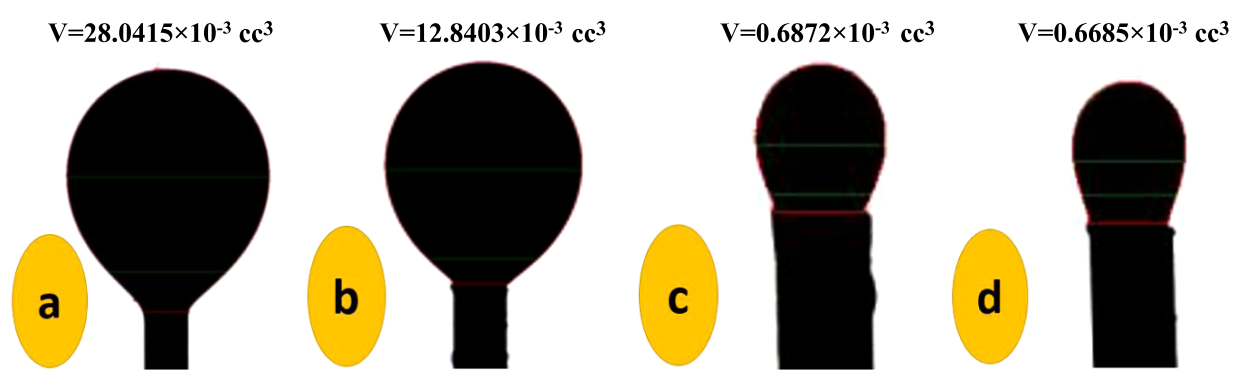

Figure 5. Digital images of pendant drop; (a): LSW and oil drop without SDBS; (b): solution of 100 ppm SDBS and oil drop; (c): solution of 5000 ppm SDBS and oil drop; (d): solution of 10000 ppm SDBS and oil drop.

hand, the CMC value of SDBS was significantly higher compared to $\mathrm{C}_{19} \mathrm{TAB}$. The IFT decreased from 28.86 to 0.82 $\mathrm{mN} / \mathrm{m}$ by increasing the concentration of SDBS from 0 to 5000 $\mathrm{ppm}$. From there, further increasing the concentration to 10000 $\mathrm{ppm}$ resulted in an IFT of $0.73 \mathrm{mN} / \mathrm{m}$.

The IFT results showed that the $C M C$ value of $\mathrm{C}_{19} \mathrm{TAB}$ is much lower than that of the SDBS. The CMC value is directly related to hydrophile-lipophile balance (HLB) value, where the lower the HLB, the lower the CMC value. The HLB value of $\mathrm{C}_{19} \mathrm{TAB}$ surfactant is about 10 , whereas this value is about 22 for SDBS surfactant. ${ }^{5,56}$ In addition, according to Kumar et al., when cationic surfactants such as $\mathrm{C}_{19} \mathrm{TAB}$ are used, the length of surfactant is proportional to the number of carbon atoms in the non-polar part (tail) of the surfactant. Longer tails then create stronger interaction between the non-polar molecules of oil and surfactant; ${ }^{20}$ thus, IFT between oil and water phase and also the $\mathrm{CMC}$ are reduced more significantly.

The IFT results were further supported by analyzing the digital images of pendant drops. Figure 4 presents the digital images of pendant drops of different solutions prepared by $\mathrm{C}_{19} \mathrm{TAB}$ surfactant. Figure $4 \mathrm{a}$ presents the oil drop in the presence of LSW without any $\mathrm{C}_{19} \mathrm{TAB}$, and Figure $4 \mathrm{~b}, \mathrm{c}, \mathrm{d}$ present the oil drops in solutions prepared by 100,335 , and 5000 ppm $\mathrm{C}_{19} \mathrm{TAB}$, respectively. The IFT values in these figures are $28.86,5.98,0.53$, and $0.49 \mathrm{mN} / \mathrm{m}$, respectively. As shown in this figure, the volume of the drop is reduced by increasing the concentration of $\mathrm{C}_{19} \mathrm{TAB}$. The largest drop is produced when LSW water phase is used $\left(28.0415 \times 10^{-3} \mathrm{~cm}^{3}\right)$, and the smallest drop is achieved when 5000 ppm $\mathrm{C}_{19} \mathrm{TAB}$ is used $(0.4278 \times$ $10^{-3} \mathrm{cc}$ ). According to Berry et al., ${ }^{58}$ a smaller drop is produced by decreasing the IFT between oil and water phase. This trend continues until CMC value is reached and further increase in the surfactant concentration has minimal effect on the drop size, as clearly shown in Figure 4. Figure 5 also presents the drop size analysis of the solutions prepared by SDBS surfactant in LSW. The same trend as above-mentioned was observed for crude oil drops in contact with SDBS solution (LSW + SDBS). The drop size was reduced significantly by increasing the SDBS concentration from 0 to $5000 \mathrm{ppm}$ in Figure 5c, while further increasing the SDBS concentration to $10000 \mathrm{ppm}$ as shown in Figure $5 \mathrm{~d}$ had no further significant effect on the drop size. These results again confirm good agreement with the IFT data, and thus confirm the interpretations of the experimental findings.

3.1.1. IFT of LSW-Surfactant-Alkali Solutions and Crude Oil. Different solutions were prepared by the addition of each surfactant at their respective CMC value combined with different concentration of $\mathrm{NaOH}(100-10000 \mathrm{ppm})$. The IFT of each solution was measured accordingly, and are tabulated in Table 5 and shown in Figure 6. Notably the IFT

Table 5. IFT Values Based on Different Concentrations of Alkali and Surfactants

\begin{tabular}{|c|c|c|c|}
\hline Test No. & Surfactant & $\mathrm{NaOH}(\mathrm{ppm})$ & IFT $(\mathrm{mN} / \mathrm{m})$ \\
\hline 1 & $335 \mathrm{ppm} \mathrm{C}_{19} \mathrm{TAB}$ & 0 & 0.53 \\
\hline 2 & 335 ppm $\mathrm{C}_{19}$ TAB & 100 & 0.35 \\
\hline 3 & $335 \mathrm{ppm} \mathrm{\textrm {C } _ { 1 9 } \mathrm { TAB }}$ & 500 & 0.23 \\
\hline 4 & $335 \mathrm{ppm} \mathrm{C}_{19} \mathrm{TAB}$ & 1000 & 0.43 \\
\hline 5 & $335 \mathrm{ppm} \mathrm{\textrm {C } _ { 1 9 } \mathrm { TAB }}$ & 5000 & 0.97 \\
\hline 6 & $335 \mathrm{ppm} \mathrm{C}_{19} \mathrm{TAB}$ & 10000 & 1.05 \\
\hline 8 & 5000 ppm SDBS & 0 & 0.82 \\
\hline 9 & 5000 ppm SDBS & 100 & 0.71 \\
\hline 10 & 5000 ppm SDBS & 500 & 0.48 \\
\hline 11 & 5000 ppm SDBS & 1000 & 0.34 \\
\hline 12 & 5000 ppm SDBS & 5000 & 0.22 \\
\hline 13 & 5000 ppm SDBS & 10000 & 0.24 \\
\hline
\end{tabular}

values showed different behaviors as a function of $\mathrm{NaOH}$ addition in the presence of different surfactants. In both cases, the IFT decreased to a minimum value, and then proceeded to rebound, but in the case of cationic $\mathrm{C}_{19} \mathrm{TAB}$ the minimum value was reached much earlier, and the rebound was much more accentuated, compared to the solution with anionic SDBS. The 


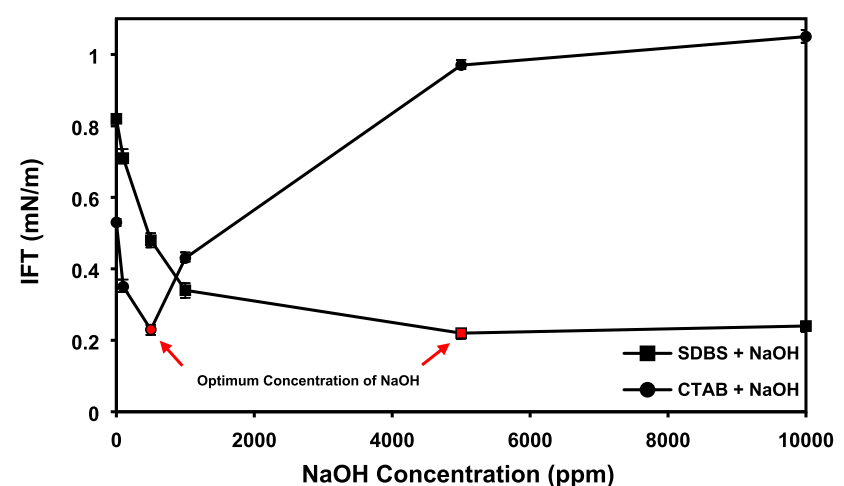

Figure 6. IFT between different LSW-surfactant-alkali solutions, prepared with varying $\mathrm{NaOH}$ and constant $\mathrm{C}_{19} \mathrm{TAB}$ (335 ppm) or SDBS (5000 ppm) at their CMC values, and crude oil.

lowest points along each line $\left(0.23 \mathrm{mN} / \mathrm{m}\right.$ for $\mathrm{C}_{19} \mathrm{TAB}$, and 0.22 $\mathrm{mN} / \mathrm{m}$ for SDBS) correspond to the optimal $\mathrm{NaOH}$ concentration in each case.

Figures 7 and 8 present the drop size analysis of solutions prepared with different concentration of $\mathrm{NaOH}$ at $\mathrm{CMC}$ concentration of $\mathrm{C}_{19} \mathrm{TAB}(335 \mathrm{ppm})$, and SDBS (5000 ppm), respectively. In both cases, the volume of each drop changes with the same trend as IFT, decreasing towards the optimum $\mathrm{NaOH}$ concentration, and then increasing again. Table S1 (in the Supporting Information) presents the IFT values for different brine, alkaline, surfactant and alkaline/surfactant solutions that were used in this study.

3.2. EC Measurements of LSW-Surfactant Solutions. Conductometry is one of the most widely used electrochemical techniques for measuring the $\mathrm{CMC}$, and is herein used to confirm the CMC values estimated from the IFT versus surfactant concentration plots. The advantages of the EC method are experimental simplicity and affordable instrumentation, and the measurement principle relies on the compositional change of the solution as a result of micelle formation, which in turn changes the conductivity of the solution. The CMC of SDBS and $\mathrm{C}_{19} \mathrm{TAB}$ solutions were determined using conventional conductivity measurement method and the results are shown in Figure 9. The EC results showed that EC value is increased with increasing the concentration of each surfactant; however, at one specific point the slope changes slightly. This point corresponds to the CMC point. ${ }^{59}$ As shown in Figure 9, the critical points are located at $335 \mathrm{ppm}$ for $\mathrm{C}_{19} \mathrm{TAB}$ and 5000 ppm for SDBS. The CMC measurement by EC is in good agreement with the IFT results, while both methods having identical CMC points identified.

Increasing the concentration of surfactants resulted in a significant decrease in the IFT, up to the CMC value, beyond which the IFT values were stabilized. In case of $\mathrm{C}_{19} \mathrm{TAB}$, the IFT decreased to $0.53 \mathrm{mN} / \mathrm{m}$ at $335 \mathrm{ppm}$, and $0.41 \mathrm{mN} / \mathrm{m}$ at 10000 ppm, respectively. In the case of SDBS, the CMC value was significantly higher, where at $5000 \mathrm{ppm}$ producing an IFT of $0.82 \mathrm{mN} / \mathrm{m}$ and at $10000 \mathrm{ppm}$ the IFT reduced slightly further to $0.73 \mathrm{mN} / \mathrm{m}$, respectively. The EC measurements are in good agreement with the IFT measurement with respect to the surfactant concentrations that correspond to the $\mathrm{CMC}$; that is $335 \mathrm{ppm}$ for $\mathrm{C}_{19} \mathrm{TAB}$ and 5000 ppm for SBDS.

The chemical reaction between the alkali and acidic components of the crude oil results in petroleum soap and emulsion formation. Consequently, the IFT between the aqueous and oleic phases is reduced, which results in a reduced capillary pressure. The acid number of crude oil, as well as its composition, are the two key factors behind these reactions. When the alkali aqueous and the oleic phases are in contact, hydroxyl ions migrate into the interface, as do organic acids, then react with each other to produce a kind of surface active agent, referred to as petroleum soap. ${ }^{29,60,61}$ The impact of alkali solution on the organic acids present in the crude oil is expressed by the following reaction, where $\mathrm{HA}$ indicates the petroleum acid and $\mathrm{A}^{-}$is an anionic surfactant:

$$
\mathrm{HA}+\mathrm{OH}^{-} \leftrightarrow \mathrm{A}^{-}+\mathrm{H}_{2} \mathrm{O}
$$

The ratio of ionized to un-ionized acid, and the rate of adsorption and desorption of ionized species at the interface are important factors affecting the IFT. The accumulation and adsorption of ionized species at the interface decreases the IFT. However, the large concentration gradient causes desorption of the active species, consequently increasing the IFT. In addition, when the ratio of ionized acid to un-ionized acid equals 1 , the minimum IFT is achieved. The main reason for the reversing phenomena observed in Figure 6 is the salting-out effect of the equilibrium shifting, which decreases the concentration of the ionized acid after CMC is achieved..$^{34,41,55}$ In addition, the formation of micelles and compression of the electric double layer at high ionic strength at higher concentrations of alkali could be another reason for this phenomenon. ${ }^{62}$

According to the results presented in the Table 5 and Figure 6, the IFT reversal for $\mathrm{C}_{19} \mathrm{TAB}$ surfactant is sharp while gradual for SDBS surfactant. Oleic soap is a water-soluble anionic surfactant, which is produced in situ by the reaction of the alkali agent with saponifiable components of the crude oil, such as carboxylic acids. This is the main role of alkali in lowering the IFT of solutions; however, their compatibility is of great importance. The compatibility of $\mathrm{NaOH}$ and surfactants is based on changes in IFT values with increasing $\mathrm{NaOH}$ concentration. According to the experimental findings in this study, it appears that SDBS and $\mathrm{NaOH}$ are very compatible while $\mathrm{C}_{19} \mathrm{TAB}$ and $\mathrm{NaOH}$ are not very compatible. $\mathrm{C}_{19} \mathrm{TAB}$ is a

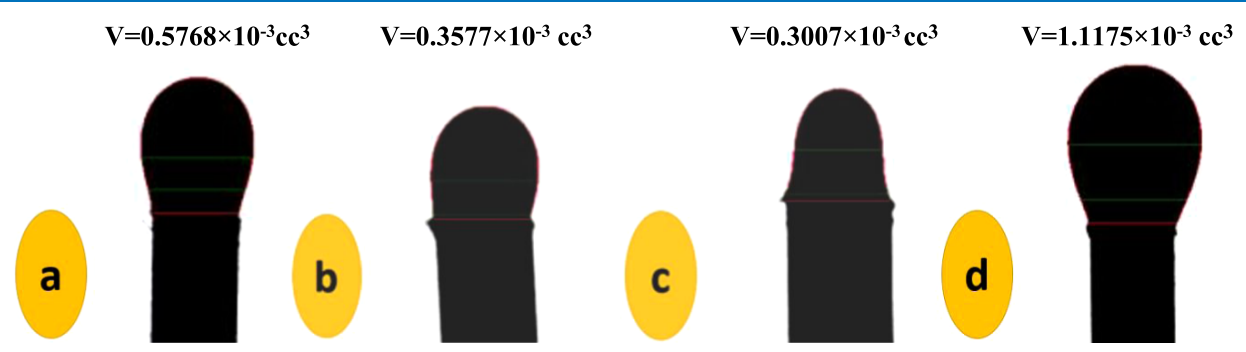

Figure 7. Digital images of pendant drops; solutions of (a) 335 ppm $\mathrm{C}_{19} \mathrm{TAB}$ and $0 \mathrm{ppm} \mathrm{NaOH}$, (b) $335 \mathrm{ppm} \mathrm{C} \mathrm{C}_{19} \mathrm{TAB}$ and $100 \mathrm{ppm} \mathrm{NaOH}$, (c) 335 ppm $\mathrm{C}_{19} \mathrm{TAB}$ and $500 \mathrm{ppm} \mathrm{NaOH}$, and (d) 335 ppm $\mathrm{C}_{19} \mathrm{TAB}$ and $10000 \mathrm{ppm} \mathrm{NaOH}$, in contact with oil drops. 

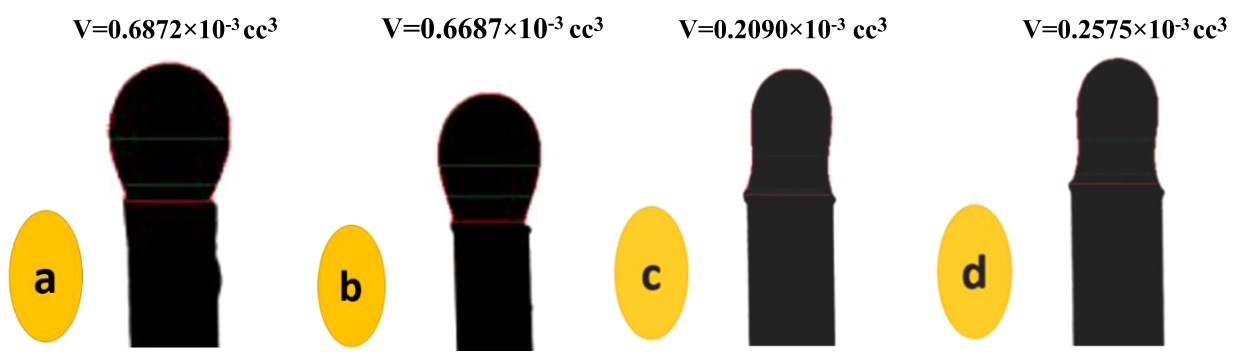

Figure 8. Digital images of pendant drops; solutions of (a) 5000 ppm SDBS and 0 ppm NaOH, (b) 5000 ppm SDBS and 100 ppm NaOH, (c) 5000 ppm SDBS and 5000 ppm NaOH, and (d) 5000 ppm SDBS and 10000 ppm NaOH, in contact with oil drops.

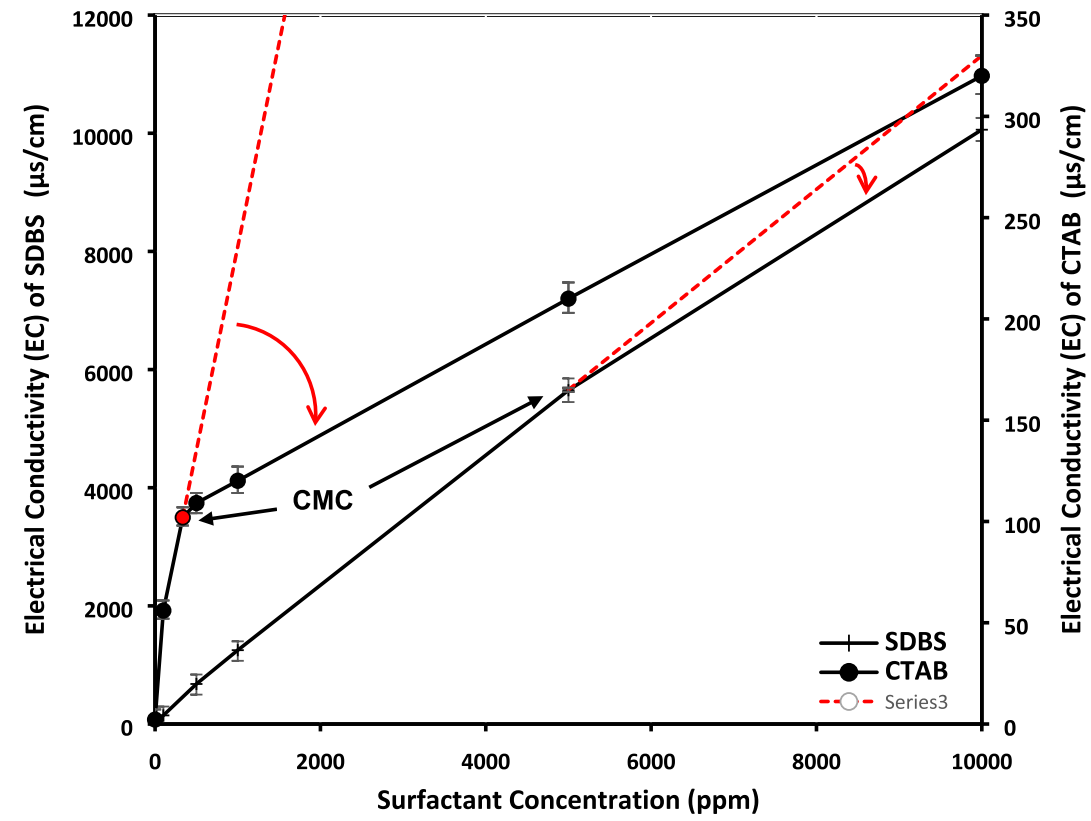

Figure 9. $\mathrm{EC}$ values of solutions with different concentrations of SDBS and $\mathrm{C}_{19} \mathrm{TAB}$; $\mathrm{EC}$ values at the surfactant concentrations that correspond to the CMC values are highlighted in red.

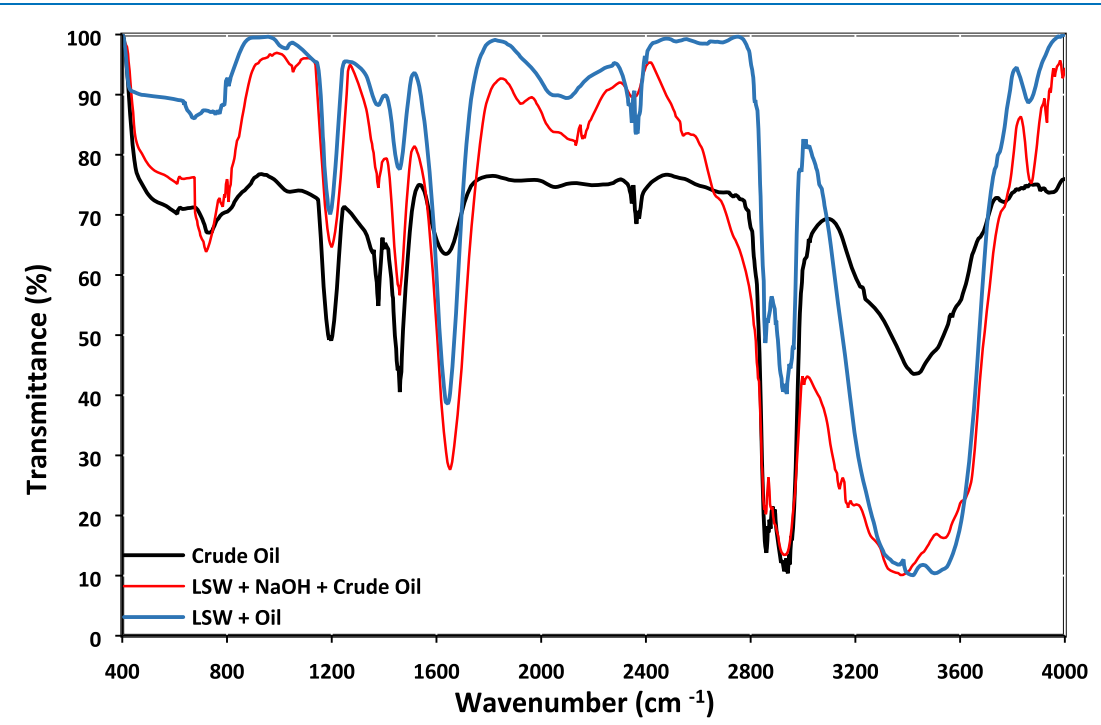

Figure 10. FT-IR spectra of raw crude oil, and crude oil contacted with LSW $+\mathrm{NaOH}$ and LSW solutions.

cationic surfactant with positive charges, while soap is anionic with negative charges. Increasing alkaline concentration increases the number of soap molecules per volume; thus, the molecules of $\mathrm{C}_{19} \mathrm{TAB}$ surfactant are attached to the molecules of soap more closely, which leads to the formation of intermolecular attraction between these molecules. However, at higher concentrations of alkali, deposition of alkali occurs, which consequently results in $\mathrm{C}_{19} \mathrm{TAB}$ surfactant and alkali loss. On the other hand, SDBS surfactant and soap have the same charges. Thus, at high concentrations of alkali, no interaction 
occurs between SDBS and soap molecules, and only ionic layers are compressed. Hence, ionization of the acid molecules is prevented, and consequently further soap production stops, which results in stability of IFT over wide range of concentrations. $^{63-65}$

3.3. FT-IR Analyses of Solution-Contacted Crude Oils. According to Samanta et al., ${ }^{41}$ the FT-IR spectrum of alkalicontacted crude oil displays approximately the same peaks as those of the original crude oil, hence no affirmative conclusion regarding the mechanisms involved could be provided. In the current study, crude oils that were contacted with LSW, LSW + alkali and LSW + alkali + surfactant were characterized by FTIR. This study first considered the mechanistic effects of LSW and alkali on crude oil and then investigated the mechanisms of surfactant-contacting solutions on crude oil, with a view of identifying synergistic effects that can benefit enhanced oil recovery. Discussion of the FT-IR spectra obtained for raw crude oil, and crude oil contacted with LSW and LSW $+\mathrm{NaOH}$ solutions are presented in Section 3.3.1, as these form the basis of discussion and are better known. In the next Sections 3.3.2 and 3.3.3, the FT-IR spectra obtained for crude oil contacted with $\mathrm{LSW}$-surfactant and $\mathrm{LSW}+\mathrm{NaOH}+$ surfactant solutions are presented, wherein new insight on the synergic effects is gained. In addition, Table S2 presents the functional groups identified in the FT-IR spectra of crude oil, alkali, surfactant and LSW solutions.

3.3.1. FT-IR Spectroscopy of Raw Crude Oil, and Crude Oil Contacted with LSW and LSW + Alkali Solutions. Figure 10 presents the FT-IR spectra of raw crude oil, and crude oil contacted with LSW and LSW $+\mathrm{NaOH}$ solutions. In addition, Table S2 (in the Supporting Information) shows the prominent functional groups present in these samples (as well as other samples latter discussed). As shown in Figure 10, specific groups of chemical bonding give rise to bands at or near the same frequency, notwithstanding of the structure of the rest of the molecule. The main functional groups identified on the IR spectra of the raw crude oil contain $\mathrm{C}-\mathrm{H}$ stretching of the saturate $\left(2858 \mathrm{~cm}^{-1}\right.$; alkanes: $\left.\mathrm{RCH}_{2} \mathrm{CH}_{3}\right),-\mathrm{CH}_{2}-$ methylene bridge $\left(2927 \mathrm{~cm}^{-1}\right), \mathrm{C}-\mathrm{C}$ in ring of aromatics $\left(1459 \mathrm{~cm}^{-1}\right)$, and $\mathrm{C}-\mathrm{H}$ symmetric deformation of the saturate $\left(1377 \mathrm{~cm}^{-1}\right)$. The peak at $729 \mathrm{~cm}^{-1}$ illustrates the presence of long chain alkyl groups $\left(\left(\mathrm{CH}_{2}\right)_{n}\right.$, with $\left.n>4\right)$ in saturates. Peaks in the wavenumber range of $1800-1600 \mathrm{~cm}^{-1}$ are attributable to carbonyl groups, such as carboxylic acids $\left(1640 \mathrm{~cm}^{-1}\right)$. Hence, the absorption at $1640 \mathrm{~cm}^{-1}$ is the reason for the presence of $\mathrm{C}=\mathrm{O}$ stretching bond of carboxylic acids or esters. In addition, two strong peaks observed at about 3423 and $2940 \mathrm{~cm}^{-1}$ are characteristic group frequencies for hydroxyl $\mathrm{O}-\mathrm{H}$ bonds resulting from aromatic (phenolic functional groups) and dimeric (carboxylic acids) vibration, respectively. Peaks attributable to the bending vibration of $\mathrm{C}-\mathrm{H}$ in methylene and methyl were observed at 1459 and $1377 \mathrm{~cm}^{-1}$, respectively. These strong bands were observed mainly due to saturate fraction of HCO. Two weak peaks at 2364 and $2346 \mathrm{~cm}^{-1}$, which are located in the region between 2440 and $2280 \mathrm{~cm}^{-1}$, are due to absorption of $\mathrm{P}-\mathrm{H}$ (phosphine) bonds. In addition, a sharp peak at $1196 \mathrm{~cm}^{-1}$ can be assigned to the presence of strong $\mathrm{C}-$ O stretch esters. ${ }^{41,66-68}$

The presence of sulfate ester and phosphate ester in the LSW $+\mathrm{NaOH}$ contacted crude oil, with three peaks at 806,1053 , and $1200 \mathrm{~cm}^{-1}$ that are attributable to $\mathrm{S}-\mathrm{OR}, \mathrm{P}-\mathrm{OR}$ and $\mathrm{P}=\mathrm{O}$, respectively, ${ }^{69}$ are seen in Figure 10. These peaks are not strong, because the concentrations of sulfate ester and phosphate ester are low in the solution. The weak peaks of $\mathrm{S}=\mathrm{O}$ bond in sulfate ester are expected to be located in the region between 1350 and $1450 \mathrm{~cm}^{-1}$, whereas two medium peaks are found at 1377 and $1459 \mathrm{~cm}^{-1}$. Therefore, peaks attributable to $\mathrm{S}=\mathrm{O}$ bond are not visible. This may be explained by both sulfate and phosphate esters being converted to sulfate and phosphate surfactants according to the hydrolysis and saponification mechanisms, with the elevated oil reservoir temperature being a factor that exacerbates this chemical reaction.

The $\mathrm{O}-\mathrm{H}$ bond in water is extremely polar, therefore there are partial negative and positive charges $(\delta$ - and $\delta+)$ on the oxygen and hydrogen, respectively. The $\mathrm{O}-\mathrm{H}$ stretching range of pure water absorption in infrared spectra is between 3100 and $4400 \mathrm{~cm}^{-1} \cdot{ }^{7070}$ In this study, some new peaks appeared by contacting LSW and LSW $+\mathrm{NaOH}$ solutions with the crude oil, including 3857, 3892, 3677, and $3658 \mathrm{~cm}^{-1}$, which are attributable to $\mathrm{O}-\mathrm{H}$ bond in water. ${ }^{71}$ According to Figure 10, two new strong peaks observed at about 3502 and $3366 \mathrm{~cm}^{-1}$ are characteristic group frequencies for hydroxyl $\mathrm{O}-\mathrm{H}$ bonded resulting from alcohol and carboxylic acid adsorption, respectively. These peaks indicate the formation of alcohols and extra carboxylic acids, which resulted from hydrolysis of esters in water. Esters are neutral compounds, unlike the acids (carboxylic acids) from which they are formed. A typical reaction is hydrolysis, wherein the alkoxy $\left(\mathrm{OR}^{\prime}\right)$ group of an ester is replaced by $\mathrm{O}-\mathrm{H}$; this reaction is known as "splitting with water". The hydrolysis of esters is catalyzed by either an acid or a base (such as $\mathrm{NaOH}$ solution). Acidic hydrolysis is simply the reverse of esterification, wherein an ester is heated with a large amount of water containing a strong-acid or -base catalyst. When an ester molecule hydrolyses with $\mathrm{H}+$ ion of water, it splits into an alcohol and a carboxylic acid molecules, ${ }^{50-52,72-75}$ as shown in Figure 11.

\begin{tabular}{|c|c|c|}
\hline$\stackrel{\mathbf{O}}{\|}$ & $\mathbf{H}^{+}$ & O \\
\hline $\mathrm{R}-\mathrm{C}-\mathrm{OR}+\mathrm{H}_{2} \mathrm{O}$ & $\longrightarrow$ & $\mathrm{R}-\mathrm{C}-\mathrm{OH}+\mathrm{ROH}$ \\
\hline
\end{tabular}

Figure 11. Hydrolysis of ester molecule to generate carboxylic acid and alcohol.

Another observation from Figure 10 was that some new peaks appeared for carboxylic acids, which was due to the addition of $\mathrm{NaOH}$ to the solution. These peaks appeared at 31723166 , $3140,3002 \mathrm{~cm}^{-1}$ (strong $\mathrm{O}-\mathrm{H}$ bond) and $1053 \mathrm{~cm}^{-1}$ (strong $\mathrm{C}-\mathrm{O}$ stretch). These peaks resulted from the base hydrolysis of esters, wherein carboxylic esters hydrolyzed to the parent carboxylic acid and an alcohol. This reaction is called saponification, because it is the basis of soap formation from glycerol triesters in fats or crude oil. This three-step process leads to acyl-oxygen cleavage, ${ }^{50,51,73-75}$ as shown in Figure 12.

The sodium salt of the soap will be formed in this case, which is an anionic carboxyl surfactant $\left(\mathrm{RCOO}^{-} \mathrm{M}^{+}\right)$. FT-IR spectrum of the $\mathrm{LSW}+\mathrm{NaOH}+$ crude oil (Figure 10) suggests the hydrolysis of esters and reaction between alkali agents and the presence of carboxylic acid groups leading to formation of surfactants in situ, which decreases the IFT between oil and water. ${ }^{41}$ Figure 13 illustrates this mechanism.

Figure 14 shows the hydrolysis of a sulfate ester molecule with an $\mathrm{H}^{+}$ion of water molecule, which generates one alkyl hydrogen sulfate and an alcohol molecule. In the next stage, one $\mathrm{Na}^{+}$ion from $\mathrm{NaOH}$ reacts with an alkyl hydrogen sulfate molecule to 


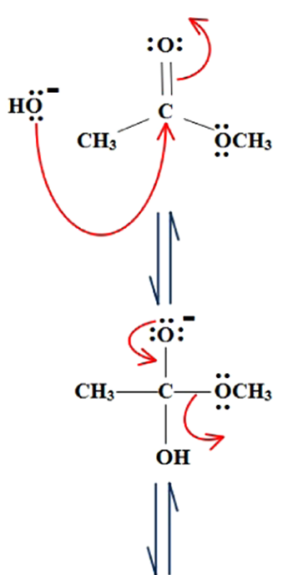

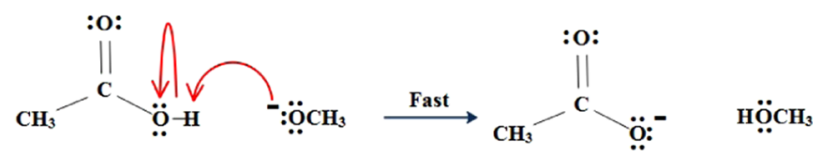

Figure 12. Saponification mechanism in crude oil induced by $\mathrm{NaOH}$, based on mechanism from ref 50 .

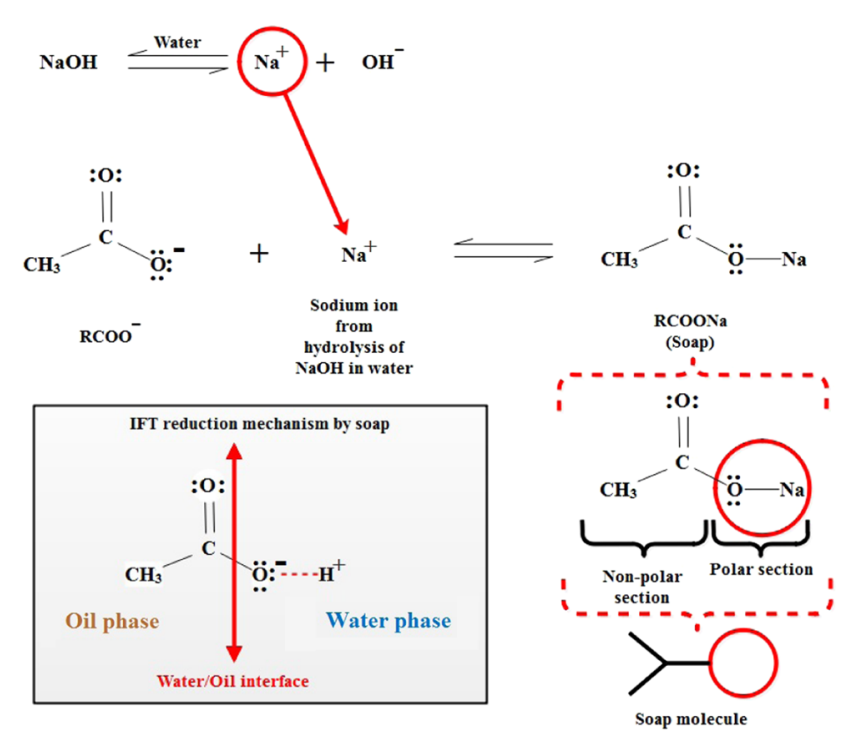

Figure 13. IFT reduction mechanism by $\mathrm{NaOH}$ at interface of oil and water.

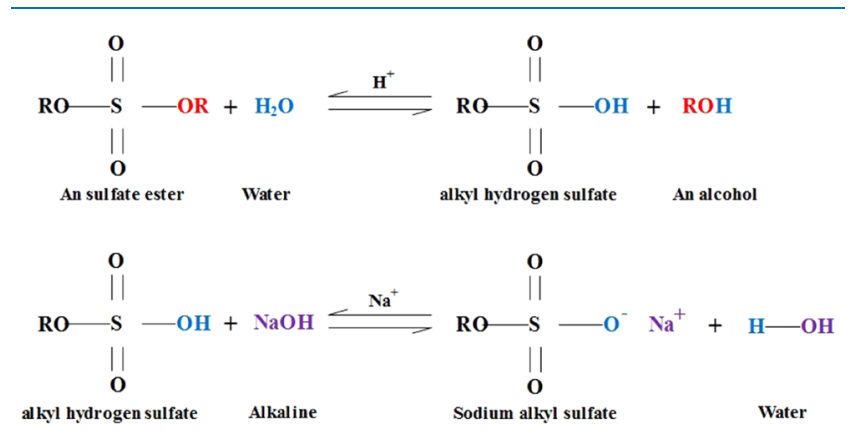

Figure 14. Hydrolysis of sulfate ester molecule and saponification by $\mathrm{NaOH}$ to generate sodium alkyl sulfate surfactant.

produce sodium alkyl sulfate surfactant $\left(\mathrm{C}_{n} \mathrm{H}_{2 n+1} \mathrm{OSO}_{2} \mathrm{ONa}\right)$ with $\mathrm{H}_{2} \mathrm{O}$. For instance, sodium lauryl sulfate is a member of these surfactant groups, referred to as sodium dodecyl sulfate (SDS). According to Figure 15, dialkyl hydrogen phosphate

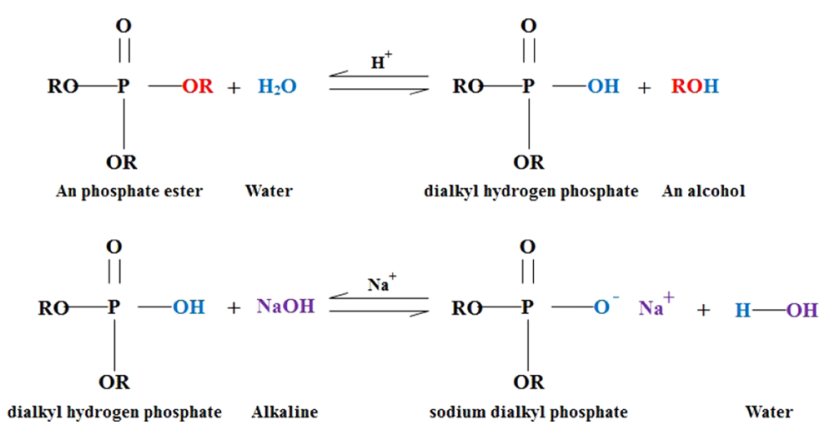

Figure 15. Hydrolysis of phosphate ester molecule and saponification by $\mathrm{NaOH}$ to generate sodium dialkyl phosphate surfactant.

results from hydrolysis of phosphate ester in water. After this stage, one dialkyl hydrogen phosphate molecule reacts with a $\mathrm{Na}^{+}$ion of alkaline to generate a molecule of sodium dialkyl phosphate surfactant $\left(\left(\mathrm{C}_{n} \mathrm{H}_{2 n+1}\right)_{2} \mathrm{HPO}_{4}\right)$. It should to be mentioned that both of these surfactants are anionic types. ${ }^{60}$ Furthermore, the concentration of carboxyl surfactants is much more than that of sulfate and phosphate surfactants due to the strong peaks of $\mathrm{C}-\mathrm{O}\left(1200 \mathrm{~cm}^{-1}\right)$ and $\mathrm{C}=\mathrm{O}\left(1651 \mathrm{~cm}^{-1}\right)$ in Figure $15^{40}$ In conclusion, alkali can react with three different types of esters present in the crude oil, including ester, sulfate ester and phosphate ester, to generate several anionic surfactants in situ, ${ }^{76-79}$ as is deemed to have occurred in the current study and to have contributed to the observed results.

3.3.2. FT-IR Spectroscopy of Crude Oil Contacted with LSW + SDBS and LSW+ Alkali+ SDBS Solutions. Figure 16 presents the FT-IR spectra of crude oil contacted with LSW + SDBS and $\mathrm{LSW}+\mathrm{SDBS}+\mathrm{NaOH}$. The addition of SDBS to the aqueous solution resulted in the formation of several new bonds. Three strong peaks at 3012,765 , and $745 \mathrm{~cm}^{-1}$ are due to $\mathrm{C}-\mathrm{H}$ stretching in aromatic benzene chain. Furthermore, the peak at $1459 \mathrm{~cm}^{-1}$ indicates the $\mathrm{C}-\mathrm{C}$ ring bond in aromatic structures, which represents the benzene chain of the SDBS molecules. Also, the strong band at $1322 \mathrm{~cm}^{-1}$ usually corresponds to the presence sulfonate $(\mathrm{S}=\mathrm{O})$ group stretching vibration, suggesting that this compound must be sodium dodecylbenzenesulfonate (SDBS). ${ }^{80,81}$

The IFT reduction mechanism with anionic SDBS surfactant addition is illustrated in Figure 17. Hydrolysis of the ester is intensified by adding alkali to the SDBS solution. Appearance of the peak at $1169 \mathrm{~cm}^{-1}$ in the FT-IR analysis of $\mathrm{NaOH}+\mathrm{SDBS}$ contacted crude oil indicates that the bulk of the esters are in the solution. Thus, production of the alcohol and carboxylic acid will also increase. As a consequence, some new peaks appear due to added $\mathrm{NaOH}$, including 3634, 3596, 3571, 3488, and 3373 $\mathrm{cm}^{-1}{ }^{3636}$ These peaks are attributable to strong $\mathrm{O}-\mathrm{H}$ bond in FT-IR analysis. As stated before, saponification process will be carried out subsequently by $\mathrm{Na}^{+}$ions. Therefore, the accumulation of SDBS and soap molecules in the interface between oil and water decreases the IFT more than the SDBS surfactant alone.

3.3.3. FT-IR Spectroscopy of Crude Oil Contacted with LSW $+C_{19} T A B$ and $L S W+$ Alkali $+C_{19} T A B$ Solutions. To analyze the interactions between cationic surfactant and crude oil in the presence and absence of alkali $(\mathrm{NaOH})$, two systems containing $\mathrm{C}_{19} \mathrm{TAB}$ were analyzed by FT-IR, as shown in Figure 18 . The bonds at the $v$ symmetric $\left(\mathrm{CH}_{3}\right)$ and $v$ asymmetric $\left(\mathrm{CH}_{3}\right)$ frequencies are observed at 2930 and $2990 \mathrm{~cm}^{-1}$, respectively. It should be mentioned that the $\mathrm{C}_{n} \mathrm{TAB}$ cationic surfactant head 


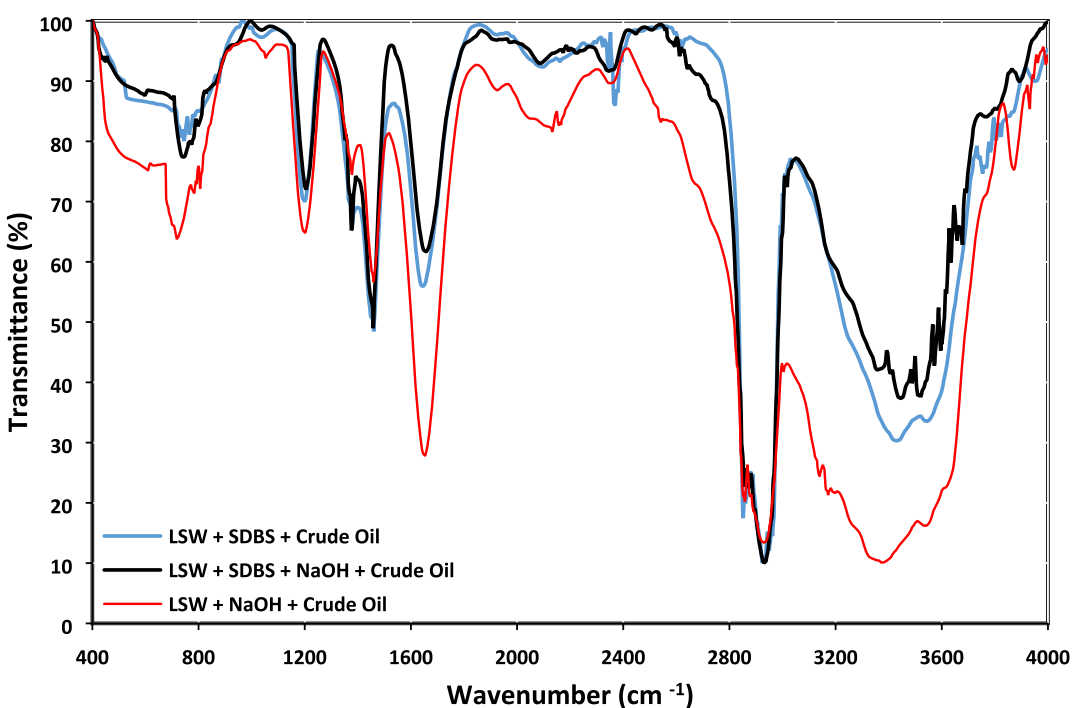

Figure 16. FT-IR spectra of crude oil contacted with LSW + SDBS, LSW + SDBS + NaOH and LSW + NaOH solutions.

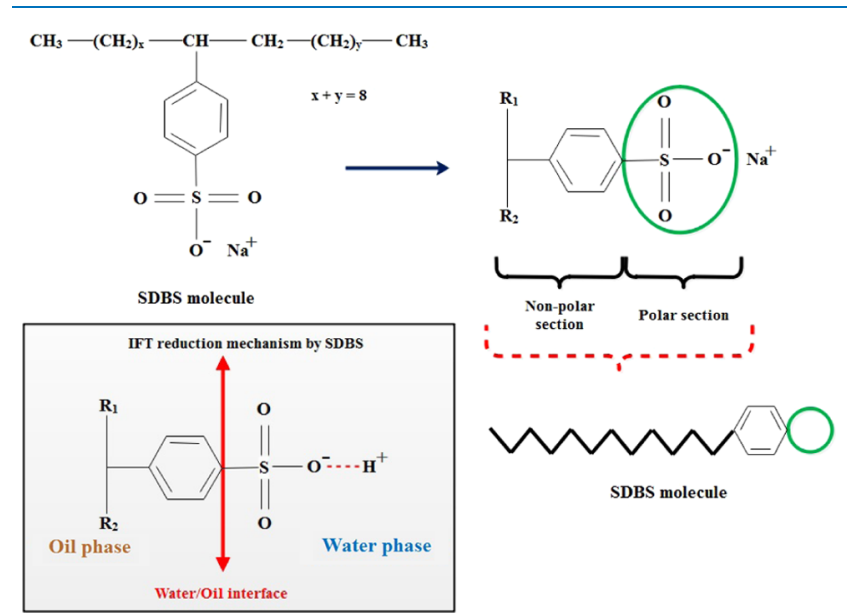

Figure 17. IFT reduction mechanism by SDBS at interface of oleic and aqueous phases. group $\left[\mathrm{N}\left(\mathrm{CH}_{3}\right)_{3}\right]^{+}$, attributable to $\left(\mathrm{CH}_{3}\right)$ stretching vibration bands, appears at approximately the same values, at 2925 and $2985 \mathrm{~cm}^{-1}$. Symmetric and asymmetric $\left(\mathrm{CH}_{3} \mathrm{~N}\right)$ bending vibration bands of the head $\left[\mathrm{N}\left(\mathrm{CH}_{3}\right)_{3}\right]$ methyl group are indistinguishable, as they appeared at $1460 \mathrm{~cm}^{-1}$ (between 1500 and $1400 \mathrm{~cm}^{-1}$ ). The peak value at $1180 \mathrm{~cm}^{-1}$ is indicative of $\mathrm{CN}^{+}$stretching vibration, which is in good agreement with the data in the literature. ${ }^{20}$ As a result of the presence of asymmetric stretching of nitrogen-oxygen linkage, the N-O peak is detected at $1520 \mathrm{~cm}^{-1}$. The ammonium ion shows a broad peak at 2544 $\mathrm{cm}^{-1}$, which is attributed to the stretching vibration of the $\mathrm{N}-\mathrm{H}$ bond. The most important peak in this system appears at the wavenumber of $935 \mathrm{~cm}^{-1}$, indicating the presence of a pivotal bond between the nitrogen atom of the ammonium ion and the $\mathrm{OH}^{-}$ion of water. In fact, after hydrolysis of $\mathrm{C}_{19} \mathrm{TAB}$ in water, the $\mathrm{Br}^{-}$ion releases from the cationic surfactant molecule and is replaced by $\mathrm{OH}^{-}$, which results in an alcohol molecule $\left(\mathrm{C}_{19} \mathrm{TAOH}\right)$ formation. ${ }^{80}$ The effect of $\mathrm{C}_{19} \mathrm{TAB}$ in IFT reduction is thus expressed by the following reaction: $\mathrm{C}_{19} \mathrm{TAB}$ $+\mathrm{OH}^{-} \rightarrow \mathrm{C}_{19} \mathrm{TAOH}+\mathrm{Br}^{-}$.

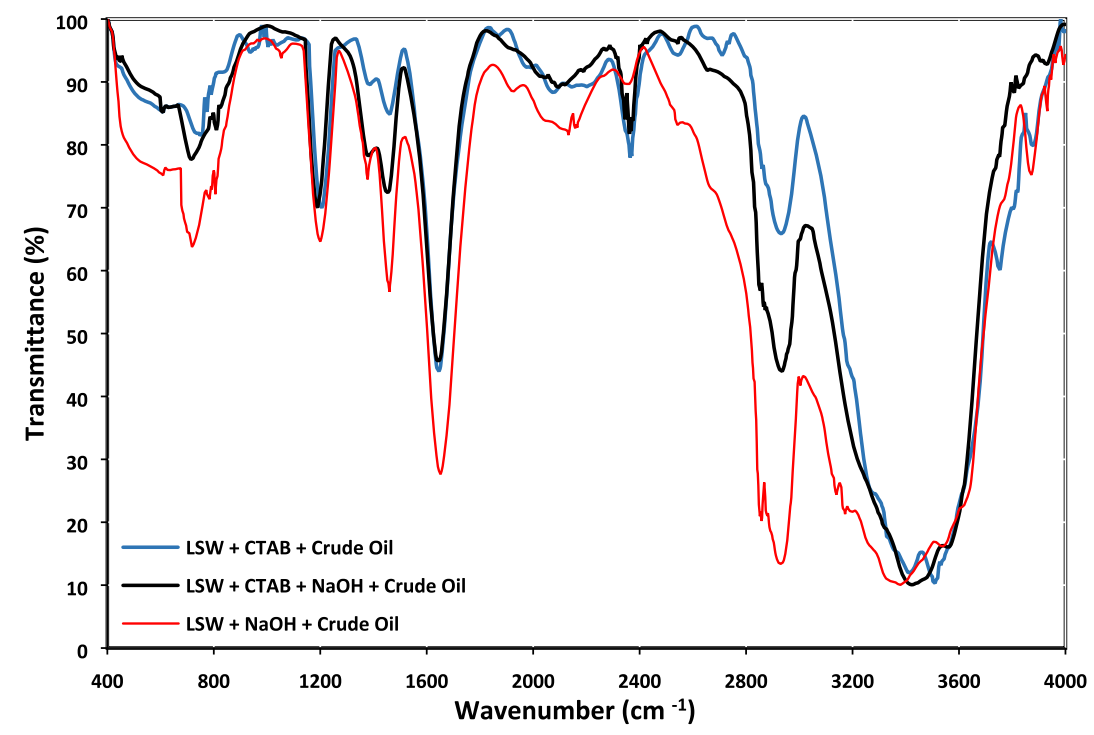

Figure 18. FT-IR spectra of crude oil contacted with $\mathrm{LSW}+\mathrm{C}_{19} \mathrm{TAB}, \mathrm{LSW}+\mathrm{C}_{19} \mathrm{TAB}+\mathrm{NaOH}$ and $\mathrm{LSW}+\mathrm{NaOH}$ solutions. 

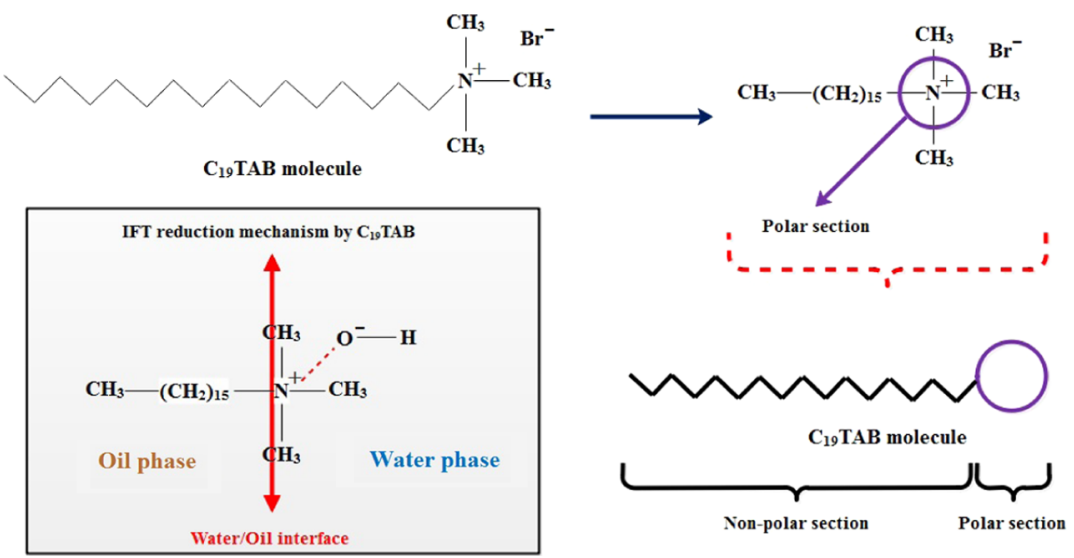

Figure 19. IFT reduction mechanism by $\mathrm{C}_{19} \mathrm{TAB}$ at interface of oleic and aqueous phases.

The $\mathrm{C}_{19} \mathrm{TAOH}$ molecules accumulate at interface of oleic and aqueous phases, which creates a strong connection between the two phases. As strong as this connection becomes, the IFT reduction will be more significant. Figure 19 shows the mechanism of IFT reduction by the cationic $\mathrm{C}_{19} \mathrm{TAB}$ surfactant. The FT-IR peak value at $2936 \mathrm{~cm}^{-1}$ corresponds to increasing the carboxylic acid production, and indicates that the hydrolysis of ester is intensified by adding $\mathrm{NaOH}$ to the $\mathrm{C}_{19} \mathrm{TAB}$ solution; thus soap is formed in the system. As explained previously, soap is a kind of anionic surfactant. Furthermore, according to literature, ${ }^{70,82,83}$ most anionic and cationic surfactants are not compatible.

\section{CONCLUSIONS}

Although significant research has been carried out on the effects of alkali and surfactants to reduce the interfacial tension between oleic and aqueous phases, there has been a lack of mechanistic understanding to define the chemical reactions between the crude oil and chemical slug in detail. Previous studies have focused on the reaction between carboxylic acids and alkali for the formation of carboxylate surfactants, which are known as soap. Moreover, hydrolysis of ester produces carboxylic acid, while crude oil also contains sulfate and phosphate esters, and the consequences of alkali reaction on their hydrolysis have not yet been investigated in the case of alkaline flooding.

This study has investigated the effectiveness of surfactant and alkali interactions at the liquid-liquid interface (oleic and water phases) for improving oil recovery at low salt concentration (i.e., with use of low salinity water for reservoir flooding). Changes in IFT, pH, EC, and FT-IR spectrum were evaluated experimentally. The results of this study showed that not only carboxylate surfactants are formed, but also another two anionic surfactants, including sodium alkyl sulfate and sodium dialkyl phosphate, are produced. In addition, the results indicate that the alkali $(\mathrm{NaOH})$ is compatible with anionic surfactants due to the similar nature of surfactants produced from alkali reactions with crude oil and anionic surfactants. In fact, all of carboxylate, sulfate, phosphate and sulfonate surfactants are anionic, with similar polar head group charge. Furthermore, cationic surfactants in concentrations close to the $\mathrm{CMC}$, along with alkali, might play a synergetic role in IFT reduction. Further increase in cationic surfactant concentration has the opposite effect, leading to sedimentation at high concentrations. On the other hand, due to salting-out effect, the solubility of polar organic species increases in the aqueous phase at low salt concentration, and LSW assists in reducing the IFT more significantly.

The following points summarize the main findings of the investigation carried out:

1. The IFT measurement showed that CMC values of $\mathrm{C}_{19} \mathrm{TAB}$ and SDBS surfactants are 335 and $5000 \mathrm{ppm}$, respectively.

2. It was found that SDBS was more compatible with $\mathrm{NaOH}$ than $\mathrm{C}_{19} \mathrm{TAB}$; however, the IFT values were reduced to the minimum values at a lower concentration with $\mathrm{C}_{19} \mathrm{TAB}$ compared to SDBS. At constant $\mathrm{CMC}$ values of $\mathrm{C}_{19} \mathrm{TAB}$ and SDBS, the minimum IFTs of 0.23 and 0.22 $\mathrm{mN} / \mathrm{m}$ were achieved at 500 and $5000 \mathrm{ppm}$ of $\mathrm{NaOH}$, respectively.

3. The IFT values at constant CMC values of surfactants showed two different behaviors with increasing $\mathrm{NaOH}$ concentration. First, IFT decreased to a certain point, then it started increasing with further increasing the $\mathrm{NaOH}$ concentration for $\mathrm{C}_{19} \mathrm{TAB}$ solutions. However, IFT reduced up to a specific concentration of $\mathrm{NaOH}$, then it became almost constant with increasing the $\mathrm{NaOH}$ concentration in SDBS solution. This optimum value of $\mathrm{NaOH}$ concentration was found to be 500 and $5000 \mathrm{ppm}$ for $\mathrm{C}_{19} \mathrm{TAB}$ and $\mathrm{SDBS}$, respectively.

4. The use of $\mathrm{NaOH}$ enhances the hydrolysis of the esters (ester, sulfate ester and phosphate ester) and produces three different types of in situ anionic surfactants, including carboxyl surfactant $\left(\mathrm{RCOO}^{-} \mathrm{M}^{+}\right)$, sodium alkyl sulfate surfactant $\left(\mathrm{C}_{n} \mathrm{H}_{2 n+1} \mathrm{OSO}_{2} \mathrm{ONa}\right)$ and sodium dialkyl phosphate surfactant $\left(\left(\mathrm{C}_{n} \mathrm{H}_{2 n+1}\right)_{2} \mathrm{HPO}_{4}\right)$.

5. The $\mathrm{pH}$ value of oil-water system increases significantly with addition of a small amount of $\mathrm{NaOH}$, which helps for IFT reduction between oleic and injected aqueous phases. Also, $\mathrm{NaOH}$ has a great potential for creating a synergy with anionic surfactants for reducing the IFT strongly in comparison with using anionic surfactants singly.

6. Using alkali and anionic surfactant is more effective than using alkali and cationic surfactant, because alkali increases $\mathrm{pH}$ value significantly and anionic surfactants work better in basic environment, while cationic surfactants have greater effectiveness in acidic conditions. 


\section{ASSOCIATED CONTENT}

\section{s) Supporting Information}

The Supporting Information is available free of charge at https://pubs.acs.org/doi/10.1021/acsomega.0c04464.

IFT measurement of different solutions (Table S1); functional groups identified in the FT-IR spectra of crude oil, alkali, surfactant and LSW solutions (Table S2) (PDF)

\section{AUTHOR INFORMATION}

\section{Corresponding Authors}

Amin Azdarpour - Department of Petroleum Engineering, Marvdasht Branch, Islamic Azad University, Marvdasht, Iran; Email:amin.azhdarpour@miau.ac.ir,aminazh22@ gmail.com

Rafael M. Santos - School of Engineering, University of Guelph, Guelph N1G 2W1, Ontario, Canada; (o orcid.org/00000002-8368-8618; Email: santosr@uoguelph.ca

\section{Authors}

Ali Esfandiarian - Department of Petroleum Engineering, Marvdasht Branch, Islamic Azad University, Marvdasht, Iran; Department of Petroleum Engineering, Fars Science and Research Branch, Islamic Azad University, Marvdasht, Iran

Erfan Mohammadian - Department of Petroleum and Natural Gas Engineering, Cyprus International University, HaspolatNicosia 99258, Northern Cyprus

Hossein Hamidi - School of Engineering, University of Aberdeen, Aberdeen AB24 3UE, Scotland, U.K.

Milad Sedaghat - Department of Petroleum Engineering Marvdasht Branch, Islamic Azad University, Marvdasht, Iran; Department of Petroleum Engineering, Fars Science and Research Branch, Islamic Azad University, Marvdasht, Iran

Parham B. Dehkordi - Department of Energy, Politecnico di Milano, Milan 20156, Italy

Complete contact information is available at:

https://pubs.acs.org/10.1021/acsomega.0c04464

\section{Notes}

The authors declare no competing financial interest.

\section{ACKNOWLEDGMENTS}

The authors would like to gratefully acknowledge and appreciate the Department of Petroleum Engineering, Faculty of Engineering, Marvdasht Islamic Azad University (Marvdasht, Iran), and the School of Engineering, University of Guelph (Guelph, Canada), for supporting this work.

\section{REFERENCES}

(1) Maghsoudian, A.; Esfandiarian, A.; Kord, S.; Tamsilian, Y.; Soulgani, B. S. Direct Insights into the Micro and Macro Scale Mechanisms of Symbiotic Effect of $\mathrm{SO}_{4}{ }^{2-}, \mathrm{Mg}^{2+}$, and $\mathrm{Ca}^{2+}$ Ions Concentration for Smart Waterflooding in the Carbonated Coated Micromodel System. J. Mol. Liq. 2020, No. 113700.

(2) Strand, S.; Puntervold, T.; Austad, T. Water Based EOR from Clastic Oil Reservoirs by Wettability Alteration: A Review of Chemical Aspects. J. Pet. Sci. Eng. 2016, 146, 1079-1091.

(3) Sedaghat, M.; Esfandiarian, A.; Azdarpour, A. In Experimental Investigation of Synergism between Low Saline Water and Surfactant-Silica Nanoparticle in Enhanced Oil Recovery Processes, 82nd EAGE Annual Conference \& Exhibition; European Association of Geoscientists \& Engineers, 2020; pp 1-5.
(4) Sedaghat, M.; Azdarpour, A.; Nafisi, M. S.; Esfandiarian, A. In Experimental Investigation of Synergism between Low Saline Water and Surfactant-Silica Nanoparticle in Enhanced Oil Recovery Processes, 82nd EAGE Annual Conference \& Exhibition; European Association of Geoscientists \& Engineers, 2018; Vol. 2018.

(5) Torrijos, I. D. P.; Puntervold, T.; Strand, S.; Austad, T.; Bleivik, T. H.; Abdullah, H. I. An Experimental Study of the Low Salinity Smart Water-Polymer Hybrid EOR Effect in Sandstone Material. J. Pet. Sci. Eng. 2018, 164, 219-229.

(6) Ahsaei, Z.; Nabipour, M.; Azdarpour, A.; Santos, R. M.; Mohammadian, E.; Babakhani, P.; Hamidi, H.; Karaei, M. A.; Esfandiarian, A. Application of Commercial Zwitterionic Surfactants and Ionic Liquids to Reduce Interfacial Tension and Alter Wettability in a Carbonate Reservoir. Energy Sources, Part A 2019, 1-12.

(7) Tian, F.; Zhao, Y.; Yan, Y.; Gou, X.; Shi, L.; Qin, F.; Shi, J.; Lv, J.; Cao, B.; Li, Y. Analysis of the Static and Dynamic Imbibition Effect of Surfactants and the Relative Mechanism in Low-Permeability Reservoirs. ACS Omega 2020, 5, 17442-17449.

(8) Bhut, P. R.; Pal, N.; Mandal, A. Characterization of Hydrophobically Modified Polyacrylamide in Mixed Polymer-Gemini Surfactant Systems for Enhanced Oil Recovery Application. ACS Omega 2019, 4, 20164-20177.

(9) Kakati, A.; Kumar, G.; Sangwai, J. S. Oil Recovery Efficiency and Mechanism of Low Salinity-Enhanced Oil Recovery for Light Crude Oil with a Low Acid Number. ACS Omega 2020, 5, 1506-1518.

(10) Jin, F.; Li, Q.; He, Y.; Luo, Q.; Pu, W. Experimental Study on Enhanced Oil Recovery Method in Tahe High-Temperature and HighSalinity Channel Sand Reservoir: Combination of Profile Control and Chemical Flooding. ACS Omega 2020, 5, 5657-5665.

(11) Wang, C.; Gao, H.; Qi, Y.; Li, X.; Zhang, R.; Fan, H. Investigation on the Mechanisms of Spontaneous Imbibition at High Pressures for Tight Oil Recovery. ACS Omega 2020, 1, No. 12727.

(12) Chen, H.; Qing, S.; Ye, Z.; Han, L.; Wang, X.; Xu, L.; Liu, Z. Experimental Investigation of Hydrophobically Modified $\alpha$-ZrP Nanosheets for Enhancing Oil Recovery in Low-Permeability Sandstone Cores. ACS Omega 2019, 4, 22178-22186.

(13) Betancur, S.; Giraldo, L. J.; Carrasco-Marín, F.; Riazi, M.; Manrique, E. J.; Quintero, H.; García, H. A.; Franco-Ariza, C. A.; Cortés, F. B. Importance of the Nanofluid Preparation for Ultra-Low Interfacial Tension in Enhanced Oil Recovery Based on SurfactantNanoparticle-Brine System Interaction. ACS Omega 2019, 4, 1617116180.

(14) Saadat, M.; Tsai, P. A.; Ho, T.-H.; Øye, G.; Dudek, M. Development of a Microfluidic Method to Study Enhanced Oil Recovery by Low Salinity Water Flooding. ACS Omega 2020, 5, No. 17521.

(15) Khalil, M.; Aulia, G.; Budianto, E.; Mohamed Jan, B.; Habib, S. H.; Amir, Z.; Abdul Patah, M. F. Surface-Functionalized Superparamagnetic Nanoparticles (SPNs) for Enhanced Oil Recovery: Effects of Surface Modifiers and Their Architectures. ACS Omega 2019, 4, 21477-21486.

(16) Austad, T.; Milter, J. In Spontaneous Imbibition of Water into Low Permeable Chalk at Different Wettabilities Using Surfactants, International Symposium on Oilfield Chemistry; Society of Petroleum Engineers, 1997.

(17) Standnes, D. C.; Austad, T. Wettability Alteration in Chalk: 1. Preparation of Core Material and Oil Properties. J. Pet. Sci. Eng. 2000, $28,111-121$.

(18) Standnes, D. C.; Austad, T. Wettability Alteration in Chalk: 2. Mechanism for Wettability Alteration from Oil-Wet to Water-Wet Using Surfactants. J. Pet. Sci. Eng. 2000, 28, 123-143.

(19) Standnes, D. C.; Austad, T. Wettability Alteration in Carbonates: Low-Cost Ammonium Surfactants Based on Bio-Derivatives from the Coconut Palm as Active Chemicals to Change the Wettability Form Oil-Wet to Water-Wet Conditions. Colloids Surf., A 2003, 218, 161173

(20) Kumar, S.; Panigrahi, P.; Saw, R. K.; Mandal, A. Interfacial Interaction of Cationic Surfactants and Its Effect on Wettability 
Alteration of Oil-Wet Carbonate Rock. Energy Fuels 2016, 30, 28462857.

(21) Standnes, D. C.; Austad, T. Nontoxic Low-Cost Amines as Wettability Alteration Chemicals in Carbonates. J. Pet. Sci. Eng. 2003, 39, 431-446.

(22) Standnes, D. C.; Austad, T. Wettability Alteration in Carbonates: Interaction between Cationic Surfactant and Carboxylates as a Key Factor in Wettability Alteration from Oil-Wet to Water-Wet Conditions. Colloids Surf., A 2003, 216, 243-259.

(23) Strand, S.; Standnes, D. C.; Austad, T. Spontaneous Imbibition of Aqueous Surfactant Solutions into Neutral to Oil-Wet Carbonate Cores: Effects of Brine Salinity and Composition. Energy Fuels 2003, 17, $1133-1144$.

(24) Honarvar, B.; Rahimi, A.; Safari, M.; Rezaee, S.; Karimi, M. Favorable Attributes of Low Salinity Water Aided Alkaline on Crude Oil-Brine-Carbonate Rock System. Colloids Surf., A 2020, 585, No. 124144.

(25) Esfandiarian, A.; Azdarpour, A. In An Experimental Investigation of Using C19TAB and $\mathrm{NaOH}$ as a Novel Chemical EOR Process in a Micromodel System, 80th EAGE Conference and Exhibition; European Association of Geoscientists \& Engineers, 2018; Vol. 2018.

(26) Sharma, H.; Dufour, S.; Arachchilage, G. W. P. P.; Weerasooriya, U.; Pope, G. A.; Mohanty, K. Alternative Alkalis for ASP Flooding in Anhydrite Containing Oil Reservoirs. Fuel 2015, 140, 407-420.

(27) Sharma, H.; Panthi, K.; Mohanty, K. K. Surfactant-Less AlkaliCosolvent-Polymer Floods for an Acidic Crude Oil. Fuel 2018, 215, 484-491.

(28) DeZabala, E. F.; Vislocky, J. M.; Rubin, E.; Radke, C. J. A Chemical Theory for Linear Alkaline Flooding. Soc. Pet. Eng. J. 1982, 22, 245-258.

(29) Sheng, J. Modern Chemical Enhanced Oil Recovery: Theory and Practice; Gulf Professional Publishing, 2010.

(30) Sheng, J. J. Status of Surfactant EOR Technology. Petroleum 2015, 1, 97-105.

(31) Dehghan, A. A.; Masihi, M.; Ayatollahi, S. Interfacial Tension and Wettability Change Phenomena during Alkali-surfactant Interactions with Acidic Heavy Crude Oil. Energy Fuels 2015, 29, 649-658.

(32) Kumar, A.; Mandal, A. Critical Investigation of Zwitterionic Surfactant for Enhanced Oil Recovery from Both Sandstone and Carbonate Reservoirs: Adsorption, Wettability Alteration and Imbibition Studies. Chem. Eng. Sci. 2019, 209, No. 115222.

(33) Chen, L.; Zhang, G.; Ge, J.; Jiang, P.; Tang, J.; Liu, Y. Research of the Heavy Oil Displacement Mechanism by Using Alkaline/surfactant Flooding System. Colloids Surf., A 2013, 434, 63-71.

(34) Liu, Q.; Dong, M.; Yue, X.; Hou, J. Synergy of Alkali and Surfactant in Emulsification of Heavy Oil in Brine. Colloids Surf., A 2006, 273, 219-228.

(35) Zhang, H.; Dong, M.; Zhao, S. Which One Is More Important in Chemical Flooding for Enhanced Court Heavy Oil Recovery, Lowering Interfacial Tension or Reducing Water Mobility? Energy Fuels 2010, 24, $1829-1836$.

(36) Shaddel, S.; Tabatabae-Nejad, S. A. Alkali/surfactant Improved Low-Salinity Waterflooding. Transp. Porous Media 2015, 106, 621642.

(37) Katende, A.; Sagala, F. A Critical Review of Low Salinity Water Flooding: Mechanism, Laboratory and Field Application. J. Mol. Liq. 2019, 278, 627-649.

(38) Chavan, M.; Dandekar, A.; Patil, S.; Khataniar, S. Low-SalinityBased Enhanced Oil Recovery Literature Review and Associated Screening Criteria. Pet. Sci. 2019, 1-17.

(39) Hosseinzade Khanamiri, H.; Baltzersen Enge, I.; Nourani, M.; Stensen, J. Å.; Torsæter, O.; Hadia, N. EOR by Low Salinity Water and Surfactant at Low Concentration: Impact of Injection and in Situ Brine Composition. Energy Fuels 2016, 30, 2705-2713.

(40) Pal, N.; Saxena, N.; Laxmi, K. V. D.; Mandal, A. Interfacial Behaviour, Wettability Alteration and Emulsification Characteristics of a Novel Surfactant: Implications for Enhanced Oil Recovery. Chem. Eng. Sci. 2018, 187, 200-212.
(41) Samanta, A.; Ojha, K.; Mandal, A. Interactions between Acidic Crude Oil and Alkali and Their Effects on Enhanced Oil Recovery. Energy Fuels 2011, 25, 1642-1649.

(42) Guo, H.; Li, Y.; Wang, F.; Yu, Z.; Chen, Z.; Wang, Y.; Gao, X. ASP Flooding: Theory and Practice Progress in China. J. Chem. 2017, 2017, No. 1.

(43) Deng, X.; Kamal, M. S.; Patil, S.; Hussain, S. M. S.; Zhou, X. A Review on Wettability Alteration in Carbonate Rocks: Wettability Modifiers. Energy Fuels 2019, 34, 31-54.

(44) McGuire, P. L.; Chatham, J. R.; Paskvan, F. K.; Sommer, D. M.; Carini, F. H. In Low Salinity Oil Recovery: An Exciting New EOR Opportunity for Alaska's North Slope, SPE Western Regional Meeting; Irvine, California, USA, 2005; pp 1-15.

(45) Pal, N.; Verma, A.; Ojha, K.; Mandal, A. Nanoparticle-Modified Gemini Surfactant Foams as Efficient Displacing Fluids for Enhanced Oil Recovery. J. Mol. Liq. 2020, No. 113193.

(46) Drexler, S.; Correia, E. L.; Jerdy, A. C.; Cavadas, L. A.; Couto, P. Effect of $\mathrm{CO} 2$ on the Dynamic and Equilibrium Interfacial Tension between Crude Oil and Formation Brine for a Deepwater Pre-Salt Field. J. Pet. Sci. Eng. 2020, No. 107095.

(47) Al-Soufi, W.; Piñeiro, L.; Novo, M. A Model for Monomer and Micellar Concentrations in Surfactant Solutions: Application to Conductivity, NMR, Diffusion, and Surface Tension Data. J. Colloid Interface Sci. 2012, 370, 102-110.

(48) Dabiri, A.; Honarvar, B. Investigation of Interfacial Tension Reduction, Wettability Alteration, and Oil Recovery Using a New Nonionic Oil-Based Surfactant from Gemini Surfactants Family Coupled with Low-Salinity Water: Experimental Study on Oil-Wet Carbonate Rock. J. Surfactants Deterg. 2020, 23, No. 821

(49) Austad, T.; RezaeiDoust, A.; Puntervold, T. SPE improved oil recovery symposium. In Chemical Mechanism of Low Salinity Water Flooding in Sandstone Reservoirs; Society of Petroleum Engineers, 2010.

(50) Carey, F. A. Carboxylic Acid Derivatives: Nucleophilic Acyl Substitution. In Organic Chemistry, 5th ed.; Oberbroeckling, S. R., Eds.; McGraw-Hill, Inc.: New York, NY, 2003; pp 830-885.

(51) Theodorou, V.; Skobridis, K.; Tzakos, A. G.; Ragoussis, V. A Simple Method for the Alkaline Hydrolysis of Esters. Tetrahedron Lett. 2007, 48, 8230-8233.

(52) da Silva, P. L.; Guimarães, L.; Pliego, J. R., Jr Revisiting the Mechanism of Neutral Hydrolysis of Esters: Water Autoionization Mechanisms with Acid or Base Initiation Pathways. J. Phys. Chem. B 2013, 117, 6487-6497.

(53) Xie, D.; Hou, J.; Zhao, F.; Doda, A. The Comparison Study of IFT and Consumption Behaviors between Organic Alkali and Inorganic Alkali. J. Pet. Sci. Eng. 2016, 147, 528-535.

(54) Kumar, A.; Mandal, A. Characterization of Rock-Fluid and FluidFluid Interactions in Presence of a Family of Synthesized Zwitterionic Surfactants for Application in Enhanced Oil Recovery. Colloids Surf., A 2018, 549, 1-12.

(55) Miraglia, D. B.; Rodríguez, J. L.; Minardi, R. M.; Schulz, P. C. Critical Micelle Concentration and HLB of the Sodium Oleatehexadecyltrimethylammonium Bromide Mixed System. J. Surfactants Deterg. 2011, 14, 401-408.

(56) Kothencz, R.; Nagy, R.; Bartha, L. Determination of HLB Values of Some Nonionic Surfactants and Their Mixtures; Universitatis BabesBolyai, Chemia, 2017; Vol. 62.

(57) Kumar, S.; Mandal, A. Studies on Interfacial Behavior and Wettability Change Phenomena by Ionic and Nonionic Surfactants in Presence of Alkalis and Salt for Enhanced Oil Recovery. Appl. Surf. Sci. 2016, 372, 42-51.

(58) Berry, J. D.; Neeson, M. J.; Dagastine, R. R.; Chan, D. Y. C.; Tabor, R. F. Measurement of Surface and Interfacial Tension Using Pendant Drop Tensiometry. J. Colloid Interface Sci. 2015, 454, 226237.

(59) Domínguez, A.; Fernandez, A.; Gonzalez, N.; Iglesias, E.; Montenegro, L. Determination of Critical Micelle Concentration of Some Surfactants by Three Techniques. J. Chem. Educ. 1997, 74, 1227. 
(60) Kamal, M. S.; Hussein, I. A.; Sultan, A. S. Review on Surfactant Flooding: Phase Behavior, Retention, IFT, and Field Applications. Energy Fuels 2017, 31, 7701-7720.

(61) Belhaj, A. F.; Elraies, K. A.; Mahmood, S. M.; Zulkifli, N. N.; Akbari, S.; Hussien, O. S. The Effect of Surfactant Concentration, Salinity, Temperature, and $\mathrm{pH}$ on Surfactant Adsorption for Chemical Enhanced Oil Recovery: A Review. J. Pet. Explor. Prod. Technol. 2019, $1-13$.

(62) Tong, M.; Liu, P.; Zhang, L.; Zhu, Y. An Improved Model for Interfacial Activity of Acidic Oil/caustic System for Alkaline Flooding. In International Meeting on Petroleum Engineering; Society of Petroleum Engineers, 1986.

(63) Zhang, H.; Dong, M.; Zhao, S. Experimental Study of the Interaction between $\mathrm{NaOH}$, Surfactant, and Polymer in Reducing Court Heavy Oil/brine Interfacial Tension. Energy Fuels 2012, 26, 3644-3650.

(64) Khan, M. Y.; Samanta, A.; Ojha, K.; Mandal, A. Design of Alkaline/surfactant/polymer (ASP) Slug and Its Use in Enhanced Oil Recovery. Pet. Sci. Technol. 2009, 27, 1926-1942.

(65) Trabelsi, S.; Hutin, A.; Argillier, J.-F.; Dalmazzone, C.; Bazin, B.; Langevin, D. Effect of Added Surfactants on the Dynamic Interfacial Tension Behaviour of Alkaline/diluted Heavy Crude Oil System. Oil Gas Sci. Technol. 2012, 67, 963-968.

(66) Aske, N.; Kallevik, H.; Sjöblom, J. Determination of Saturate, Aromatic, Resin, and Asphaltenic (SARA) Components in Crude Oils by Means of Infrared and near-Infrared Spectroscopy. Energy Fuels 2001, 15, 1304-1312.

(67) Douda, J.; Alvarez, R.; Navarrete Bolaños, J. Characterization of Maya Asphaltene and Maltene by Means of Pyrolysis Application. Energy Fuels 2008, 22, 2619-2628.

(68) Dickie, J. P.; Yen, T. F. Macrostructures of the Asphaltic Fractions by Various Instrumental Methods. Anal. Chem. 1967, 39, $1847-1852$

(69) Hampton, C.; Demoin, D.; Glaser, R. E. Vibrational Spectroscopy Tutorial: Sulfur and Phosphorus; University of Missouri, 2010.

(70) Rosen, M. J.; Kunjappu, J. T. Surfactants and Interfacial Phenomena; John Wiley \& Sons, 2012.

(71) Nicolaisen, F. M. IR Absorption Spectrum (4200-3100 Cm-1) of $\mathrm{H} 2 \mathrm{O}$ and $(\mathrm{H} 2 \mathrm{O}) 2$ in CCl4. Estimates of the Equilibrium Constant and Evidence That the Atmospheric Water Absorption Continuum Is due to the Water Dimer. J. Quant. Spectrosc. Radiat. Transfer 2009, 110, 2060-2076.

(72) Roberts, I.; Urey, H. C. The Mechanisms of Acid Catalyzed Ester Hydrolysis, Esterification and Oxygen Exchange of Carboxylic Acids. J. Am. Chem. Soc. 1939, 61, 2584-2587.

(73) Jencks, W. P.; Carriuolo, J. General Base Catalysis of Ester Hydrolysis1. J. Am. Chem. Soc. 1961, 83, 1743-1750.

(74) Stefanidis, D.; Jencks, W. P. General Base Catalysis of Ester Hydrolysis. J. Am. Chem. Soc. 1993, 115, 6045-6050.

(75) Johnson, S. L. General Base and Nucleophilic Catalysis of Ester Hydrolysis and Related Reactions. In Advances in Physical Organic Chemistry; Elsevier, 1967; Vol. 5, pp 237-330.

(76) Bethell, D.; Fessey, R. E.; Namwindwa, E.; Roberts, D. W. The Hydrolysis of C 12 Primary Alkyl Sulfates in Concentrated Aqueous Solutions. Part 1. General Features, Kinetic Form and Mode of Catalysis in Sodium Dodecyl Sulfate Hydrolysis. J. Chem. Soc., Perkin Trans. 2 2001, 1489-1495.

(77) Roy, A. B. The Hydrolysis of Sulfate Esters. In The Enzymes; Elsevier, 1971; Vol. 5, pp 1-19.

(78) Florián, J.; Warshel, A. Phosphate Ester Hydrolysis in Aqueous Solution: Associative versus Dissociative Mechanisms. J. Phys. Chem. B 1998, 102, 719-734.

(79) Cooper, R. S. Anionic Phosphate Surfactants. J. Am. Oil Chem. Soc. 1963, 40, 642-645.

(80) Viana, R. B.; da Silva, A. B. F.; Pimentel, A. S. Infrared Spectroscopy of Anionic, Cationic, and Zwitterionic Surfactants. Adv. Phys. Chem. 2012, 2012, 7980-7993.

(81) Sperline, R. P.; Song, Y.; Freiser, H. FTIR-ATR Study of the CoAdsorption of Benzophenone with Sodium Dodecyl Sulfate and
Sodium Dodecylbenzenesulfonate Using Al2O3-Coated Optics. Colloids Surf., A 1994, 93, 111-126.

(82) Kume, G.; Gallotti, M.; Nunes, G. Review on Anionic/cationic Surfactant Mixtures. J. Surfactants Deterg. 2008, 11, 1-11.

(83) Rosen, M. J.; Hua, X. Y. Synergism in Binary Mixtures of Surfactants: II. Some Experimental Data. J. Am. Oil Chem. Soc. 1982, 59, $582-585$. 